\title{
LA PRAXIS DE LAS RELACIONES INTERGUBERNAMENTALES EN ESPAÑA: UN EXAMEN CUANTITATIVO Y CUALITATIVO DE LA COOPERACIÓN EN MATERIA AMBIENTAL ${ }^{1}$
}

\author{
DYNAMICS OF INTERGOVERNMENTAL RELATIONS IN SPAIN: A \\ QUANTITATIVE AND QUALITATIVE ANALYSIS OF INTERGOVERNMENTAL \\ COOPERATION WITH REGARD TO ENVIRONMENTAL PROTECTION
}

\author{
MARIACHIARA ALBERTON \\ Investigadora de derecho ambiental \\ Institute for Comparative Federalism, EURAC Research \\ mariachiara.alberton@eurac.edu
}

Fecha de recepción: 17 de septiembre de 2020 / Fecha de aceptación: 2 de diciembre de 2020

RESUMEN: Uno de los retos de un sistema descentralizado como el español es asegurar la cooperación intergubernamental, promoviendo así una gobernanza ambiental eficaz en múltiples niveles. Este artículo intenta arrojar luz sobre los instrumentos de cooperación existentes entre el Estado y las Comunidades Autónomas en materia de medio ambiente. Basándose en una amplia recopilación de datos, los hallazgos empíricos muestran que la actual cooperación

\footnotetext{
${ }^{1}$ Quisiera expresar mi agradecimiento al Institut d'Estudis de l'Autogovern (IEA) de la Generalitat de Catalunya por el apoyo a la investigación llevada a cabo y a los compañeros y compañeras del Centre d'Estudis de Dret Ambiental de Tarragona (CEDAT) de la Universitat Rovira i Virgili, de Tarragona, por la colaboración prestada en todo momento. Asimismo, quisiera manifestar mi agradecimiento a los profesores Lucía Casado Casado y Jordi Jaria Manzano por las conversaciones mantenidas sobre el tema, así como por las informaciones suministradas, y Endrius Cocciolo por la traducción. En cualquier caso, la responsabilidad por el contenido del presente trabajo recae completamente en su autora.
} 
intergubernamental (principalmente a través de los mecanismos de la Conferencia Sectorial de Medio Ambiente y las Comisiones Bilaterales), aunque no sea baladí, resulta aún frágil en un supuesto de competencia compartida que va más allá de la ejecución común de actividades administrativas. En consecuencia, resulta determinante el papel del Tribunal Constitucional en lo que respecta al ejercicio de las competencias ambientales compartidas.

RESUM: Un dels reptes d'un sistema descentralitzat com l'espanyol és assegurar la cooperació intergovernamental, promovent així una governança ambiental eficaç en múltiples nivells. Aquest article intenta donar llum sobre els instruments de cooperació existents entre l'Estat i les comunitats autònomes en matèria de medi ambient. Basant-se en un ampli recull de dades, les dades empíriques mostren que l'actual cooperació intergovernamental (principalment a través dels mecanismes de la Conferència Sectorial de Medi Ambient i les comissions bilaterals), encara que no sigui intranscendent, resulta encara fràgil en un supòsit de competència compartida que va més enllà de l'execució comuna d'activitats administratives. En conseqüència, resulta determinant el paper de l'Tribunal Constitucional pel que fa a l'exercici de les competències ambientals compartides.

ABSTRACT: One of the challenges of a decentralized system like Spain is ensuring intergovernmental cooperation, thus promoting an effective multi-level environmental governance. This article attempts to shed some light on the existing forms of cooperation between State and Autonomous Communities in the environmental field. Drawing on extensive data collection, empirical findings show that current intergovernmental cooperation (mainly through the mechanisms of the Environmental Sectorial Conference and Bilateral Commissions), even though not negligible, is still fragile in the event of shared competence that goes beyond the common implementation of administrative activities. Thus the role of the Constitutional Court is likely to be pre-eminent with regard to the exercise of shared environmental competences. 
PALABRAS CLAVE: Relaciones intergubernamentales - Gobernanza multinivel del medio ambiente - Cooperación, colaboración y coordinación intergubernamental - Conferencias sectoriales - Comisiones bilaterales.

PARAULES CLAU: Relacions intergovernamentals- Governança multinivell del medi ambient - Cooperació, col-laboració i coordinació intergovernamentalConferències sectorials - Comissions bilaterals

KEYWORDS: Intergovernmental relations - multilevel environmental governance institutional cooperation, collaboration, coordination - Sectoral conferences Bilateral Commissions.

SUMARIO: I. INTRODUCCIÓN; II. LAS DINÁMICAS RELACIONALES INTERGUBERNAMENTALES EN MATERIA AMBIENTAL: UN EXAMEN CUANTITATIVO Y CUALITATIVO; 1. La Conferencia sectorial de medio ambiente; 2 . La cooperación bilateral sobre el medio ambiente: las Comisiones bilaterales de cooperación; III. LA COOPERACIÓN HORIZONTAL: UNA APROXIMACIÓN; IV. UN COTEJO CON LOS DATOS DE LA JURISPRUDENCIA CONSTITUCIONAL; V. CONCLUSIONES; VI. BIBLIOGRAFÍA.

\section{INTRODUCCIÓN}

El marco constitucional español en materia de medio ambiente se presenta como extremadamente complejo y se caracteriza por las competencias ambientales compartidas entre Estado y Comunidades Autónomas ${ }^{2}$, por una diferenciación en la misma materia que se concreta tanto en sede estatutaria como en el ejercicio del

\footnotetext{
${ }^{2}$ De acuerdo con lo que dispone el artículo 148.1.9 CE, las Comunidades Autónomas pueden, en principio, asumir en sus Estatutos de Autonomía todas las competencias ejecutivas en materia de protección del medio ambiente; en cambio, del artículo 149.1.23 CE se deriva que el Estado dispone de la competencia exclusiva para dictar la legislación básica sobre protección del medio ambiente, mientras que las Comunidades Autónomas disfrutan del desarrollo legislativo de la legislación básica estatal y pueden dictar normas adicionales de protección. El Tribunal Constitucional ha intentado, a lo largo de los años, delimitar el perímetro de las respectivas funciones. Vid:: SSTC 64/1982, 170/1989, 149/1991, 102/1995, 196/1996, 90/2000, 101/2005, 31/2010, 161/2014, 141/2016. Más recientemente, en las STC 53/2017 y STC 118/2017, el Tribunal reitera los elementos caracterizantes la legislación básica, que había sido sistematizados por la STC 101/2005.
} 
poder legislativo y administrativo, así como por la transversalidad ${ }^{3}$ y la conexión ${ }^{4}$ del medio ambiente con ámbitos distintos en las que inciden otros títulos competenciales.

Esta complejidad competencial requeriría un sistema reforzado de coordinación y cooperación entre los entes territoriales con el fin de alcanzar una política ambiental eficaz. Sin embargo, el mosaico constitucional y estatutario no aporta un sistema adecuado de relaciones institucionales.

En efecto, la Constitución no establece una segunda cámara de representación territorial efectiva ${ }^{5}$. Asimismo, faltan las referencias a los mecanismos de conexión vertical entre niveles de gobierno dirigidos a facilitar el ejercicio conjunto de las competencias asignadas. En lugar de ello, se ha ido conformando un modelo que favorece dinámicas potencialmente competitivas y conflictivas. La única previsión expresa sobre cooperación se encuentra en el art. 145.2 CE que, tras rechazar la federación de Comunidades Autónomas en el art. 145.1 CE, se refiere a las relaciones entre Comunidades Autónomas ${ }^{6}$. Esta norma, sin embargo, planteó desde el principio una serie de cuestiones críticas $^{7}$, que han derivado en la escasa

${ }^{3}$ Por ejemplo, art. $149.1 \mathrm{CE}$, apartados: 1. condiciones básicas de igualdad de todos los ciudadanos, 3. relaciones internacionales y 13. bases y coordinación de la planificación general de la actividad económica. En particular, algunos de estos títulos competenciales utilizados por el Estado han llegado a adquirir una gran expansividad, condicionando de forma decisiva el ejercicio de competencias ambientales por las Comunidades Autónomas, como advierte: L. Casado Casado en La recentralización de competencias en materia de protección del medio ambiente, Generalitat de Catalunya, Col lecció IEA, Barcelona, 2018, p. 230.

4 Existe un elevado número de materias íntimamente ligadas al título "protección del medio ambiente", que cuentan con un reparto competencial específico (régimen minero y energético, pesca en aguas interiores y marítima, caza y pesca fluvial, ordenación del territorio, urbanismo y vivienda). 5 Vid.: T. Font i Llovet-F. Merloni, "Il regionalismo spagnolo tra riforma costituzionale e riforma statutaria", Le Regioni, 33, 6, 2005, pp. 1179-1202.

${ }^{6}$ Para profundizar en el artículo 145.2 CE, nos remitimos a: A. Sánchez Navarro, "Artículo 145. Convenios entre Comunidades Autónomas", en Óscar Alzaga Villamil, (dir.), Comentarios a la Constitución Española de 1978, XI, Madrid, Edersa, 1999; J. Tajadura Tejada, "El artículo 145 de la Constitución Española: los convenios y acuerdos de cooperación entre las CC.AA.", en Revista Jurídica de Navarra, núm. 21, 1996; C. Gutiérrez Vicen, "La Intervención de las Cortes Generales en la celebración de convenios entre Comunidades Autónomas: la aparición de nuevos problemas", en Corts, Anuario de Derecho Parlamentario, núm. 9, 2000, p. 283 ss. Vid.: F. J. Matia Portilla, "La cooperación horizontal: Un impulso tan necesario como esperado", en Revista Jurídica de Castilla y León, núm. 23, 2011.

7 Por ejemplo, tal como ha sido posteriormente aclarado por el Tribunal Constitucional (STC 44/1986), el art. 145 CE no habilita a las Comunidades Autónomas para celebrar convenios o acuerdos entre ellas, sino, presuponiendo esta capacidad, por una parte, establece los requisitos para esta materia en los estatutos, y por otra parte, determina el control del Parlamento sobre los 
aplicación del principio de cooperación horizontal, por lo menos en los primeros años de la historia constitucional española ${ }^{8}$.

No obstante, ante la omisión de una referencia a los instrumentos de conexión entre el Estado y las Comunidades Autónomas en la Constitución, se ha intentado suplir mediante la interpretación del Tribunal Constitucional ${ }^{9}$, a la que se suma, en el tiempo, la previsión de normas específicas acerca de "órganos para la cooperación entre ambas (Estado y Comunidades), de composición bilateral o multilateral, de ámbito general o de ámbito sectorial, en aquellas materias en las que exista

acuerdos de cooperación. Sobre el tema vid. J. Tajadura Tejada, "El artículo 145 de la Constitución Española: los convenios y acuerdos de cooperación entre las CC.AA." cit. Señala este autor: "El precepto parece haber sido redactado con la finalidad de que no sea utilizado. La dificultad procedimental que establece hace prácticamente inviable la cooperación interautonómica y, lo que es más grave, deja en manos de las Cortes una decisión política, la de cooperar o no, que debería corresponder, en principio, a las propias Comunidades." (p.115).

${ }^{8}$ Aunque un estudio en profundidad de la praxis revele un situación distinta de la esperada en la medida en que delata una colaboración para nada inexistente aunque oculta. Vid.: C. Colino Cámara, "Federalismo horizontal en el Estado autonómico. La evolución de los mecanismos de cooperación horizontal en España", en Cuadernos Manuel Giménez Abad, 2, 2011.

${ }^{9}$ El Tribunal Constitucional, aún apuntando a posible formas de cooperación, ha dejado siempre un amplio margen de discrecionalidad a las partes (Estado y Comunidades) en la determinación de las formas más oportunas. Por ejemplo, vid.: STC 18/1982, 76/1983, 77/1984, 95/1986, 227/1988, 80/1989, 214/1989, 45/1991, 13/1992, 102/1995, 118/1998, 194/2004. Posteriormente, vid.: STC 53/2017: "También ha reiterado este Tribunal que el citado principio de cooperación impone que se arbitren mecanismos o cauces de colaboración mutua a fin de evitar interferencias y, en su caso, dispersión de esfuerzos e iniciativas perjudiciales para la finalidad prioritaria (SSTC 13/1988, (F. j. 2); 102/1995, (F.j. 31), aunque, por lo general, no prejuzga cuál debe ser la correcta técnica a través de cuya mediación dicha coparticipación se articule (STC 68/1996 F.j. 10... Así pues, este Tribunal ha venido reconociendo un margen de discrecionalidad en la determinación de los específicos mecanismos cooperativos, lo que no implica que dicho margense conciba como un espacio totalmente inmune al control jurisdiccional (SSTC118/1998, (FJ 12), 195/2012, (FJ 5)". Destaca la STC 31/2010, en la que se afirma, en el ámbito de la cooperación, la superioridad del Estado sobre las Comunidades Autónomas: "Dicha relación, amén de no ser excluyente de la multilateralidad, como el propio precepto impugnado reconoce, no cabe entenderla como expresiva de una relación entre entes políticos en situación de igualdad, capaces de negociar entre sí en tal condición, pues, el Estado siempre ostenta una posición de superioridad respecto de las Comunidades Autónomas (STC 4/1981, FJ 3). De acuerdo con ello el principio de bilateralidad sólo puede proyectarse en el ámbito de las relaciones entre órganos como una manifestación del principio general de cooperación, implícito en nuestra organización territorial del Estado". (FJ 13). Para profundizar en la sentencia, nos remitimos a: M. Corretja, J. Vintró, X. Bernadí, "Bilateralidad y multilateralidad. La participación de la Generalitat en políticas y organismos estatales, y la Comisión Bilateral", en Revista de Estudis Autonòmics i Federals, núm. 12, 2011, pp. 403-446; N. París, "Les relacions institucionals de la Generalitat en la sentència sobre l'Estatut d'Autonomia de Catalunya", en Revista Catalana de Dret Públic, Especial Sentència 31/2010 del Tribunal Constitucional, sobre l'Estatut d'Autonomia de Catalunya, 2010; M.M. Pérez Velasco, "Comentari de la Sentència del Tribunal Constitucional que resol el recurs d'inconstitucionalitat presentat pel PP contra l'Estatut d'autonomia de Catalunya: Comissió Bilateral Generalitat-Estat (article 183 EAC)", en Revista Catalana de Dret Públic. Especial Sentència 31/2010 del Tribunal Constitucional, sobre l'Estatut d'Autonomia de Catalunya, 2010. 
interrelación competencial, y con funciones de coordinación o cooperación según los casos" (Art. 145 de la ley 40/2015).

Un primer elemento normativo se encuentra en la Ley 12/1983, de 14 de octubre, del Proceso autonómico, que regula la institución de las Conferencias sectoriales entre Ministros del Estado y representantes de los órganos ejecutivos de las Comunidades con "el fin de intercambiar puntos de vista y examinar en común los problemas de cada sector y las acciones proyectadas para afrontarlos y resolverlos". Entre estas Conferencias, se han constituido la Conferencia Sectorial de Medio Ambiente ${ }^{10}$ y la Conferencia para Asuntos Europeos ${ }^{11}$, que adquieren la función de enlace multilateral para las políticas ambientales y europeas. Posteriormente, la Ley 30/1992, de 26 de noviembre, de Régimen Jurídico de las Administraciones Públicas y del Procedimiento Administrativo Común ${ }^{12}$, modificada por la Ley 4/1999, se refirió también a la cooperación entre administraciones públicas e introdujo un elenco no exhaustivo de mecanismos e instrumentos de cooperación vertical ${ }^{13}$.

${ }^{10}$ Creada en 1988 y luego constituida formalmente tras la Ley 30/1992.

11 Conferencia para Asuntos Relacionados con las Comunidades Europeas (CARCE), luego denominada CARUE tras la reunión de 15 abril de 2010. La Conferencia se creó en 1989 y se constituyó formalmente tras la ley 30/1992 mediante el acuerdo de 29 octubre de 1992, después complementado por el Acuerdo sobre Participación Interna de las Comunidades Autónomas en los asuntos comunitarios europeos a través de las Conferencias Sectoriales, de junio de 1994, por el que se prevé la partecipación de las Comunidades Autónomas en la "fase ascendente" del proceso europeo de toma de decisiones. La ley posterior 2/1997 reforzó las funciones de cooperación y el acuerdo del 9 diciembre 2004 estableció la participación directa de las Comunidades en cuatro formaciones del Consejo UE, entre las cuales aquella en materia de medio ambiente. Vid. la página web del Ministerio de Política Territorial y Función Pública, accesible en <https://www.mptfp.gob.es/portal/politica-territorial/internacional/ue/ccaa-eell-ue/CARUE.html>

[Último acceso: 28.7.2020].

12 Puede verse un amplio análisis de las previsiones en: AA. VV., Las relaciones interadministrativas de cooperación y colaboración: Seminario celebrado en Barcelona el 7 de mayo de 1993, Colección Institut d'Estudis Autonomics, Generalitat de Catalunya. Barcelona, 1993; A. Jiménez Blanco, "De las Administraciones Públicas y sus relaciones", en Comentario sistemático a la Ley de Régimen Jurídico de las Administraciones Públicas y del procedimiento administrativo común, Civitas. Madrid, 1993; J. L. Beltrán Aguirre, "Los principios organizativos de la Administración social: descentralización, participación, coordinación y cooperación", en Documentación Administrativa, 2005, pp. 207-236; P., García Mexia, "Las relaciones institucionales entre las Comunidades Autónomas. La cooperación interautonómica", en A.A.V.V. (dir.), Curso de Derecho Publico de las Comunidades Autónomas, INAP-Montecorvo. Madrid, 2003, pp. 533-577.

13 Vid.: M. J. Ridaura Martínez, Relaciones Intergubernamentales: Estado-Comunidades Autónomas, Tirant lo Blanch. Valencia, 2009, pp. 79-80. También el Tribunal Constitucional reitera la posiblidad de un margen de discrecionalidad en la determinación de los distintos instrumentos de cooperación en la STC 194/2004 (F.J. 9), que cita las anteriores SSTC 118/1998, 68/1996, 146/1992, 13/1992, 95/1986, 76/1983. 
Finalmente, la ley 40/2015, de 1 de octubre, de Régimen Jurídico del Sector Público, que, junto con la ley 39/2015, de 1 de octubre, del Procedimiento Administrativo Común de las Administraciones Públicas, ha derogado definitivamente la precedente ley 30/1992. La nueva Ley proclama, en los arts. 3 y 140, entre los principios generales, que las administraciones deben respetar en el ámbito de sus relaciones, el principio de cooperación y regula, en los arts. 143-153, las formas y los órganos de cooperación con más precisión que lo previsto anteriormente. Sin embargo, queda abierta la posibilidad de introducir otras tipologías de cooperación más allá de aquellas expresamente previstas ${ }^{14}$.

A su vez, los Estatutos de Autonomía reformados introducen títulos dedicados a la dimensión relacional en forma bilateral y multilatera ${ }^{15}$ y mencionan los principios de lealtad institucional, cooperación y solidaridad ${ }^{16}$.

Sobre la base de esta sintética reconstrucción del marco normativo ${ }^{17}$, conscientes de que la perspectiva de la sola consideración del dato normativo no es suficiente para captar la realidad de la cuestión de las relaciones intergubernamentales que se han consolidado en el ordenamiento español, se procede a continuación a la identificación de las formas y de las funciones de las relaciones interinstitucionales que se han fijado en la praxis, con especial énfasis en la gestión y protección ambiental y en el reconocimiento de los límites y de los incentivos surgidos en la cooperación, mediante un análisis tanto cuantitativo como cualitativo.

14 Vid:: M. Zambonino Pulito, "La articulación de la gobernanza multinivel a través de técnicas orgánicas de colaboración, cooperación y coordinación”, en Revista Aragonesa de Administración Pública, núm. 52, 2018, pp. 230-263.

${ }^{15}$ Vid. los Estatutos de Autonomía de: Comunidad Valenciana (Títulos V y VI), Cataluña (Título V), Andalucía (Título IX), Islas Baleares (Título VII), Castilla y León (Título IV) y Aragón (Título VII).

${ }^{16}$ Vid:: M. J. García Morales, "Los nuevos Estatutos de Autonomía y las nuevas relaciones de colaboración. Un nuevo escenario, ¿una nueva etapa?", en Revista Jurídica de Castilla y León, núm. 19, 2009, pp. 364-367; P. Biglino Campos, "La lealtad constitucional en el Estado de las Autonomía", en Revista Jurídica de Castilla y León, núm. extraordinario, 2004.

${ }_{17}$ Para un análisis en profundidad de las consecuencias de las intervenciones regulatorias y de las correspondientes decisiones del Tribunal Constitucional ya mencionadas en materia de relaciones intergubernamentales (incluida la Ley Orgánica de Armonización del Proceso Autonómico (LOAPA) declarada inconstitucional por el Tribunal Constitucional en la STC 76/1983) se remite a: J. M. Pérez Medina, "Dinámica de las conferencias sectoriales. Entre la intergubernamentalidad y la cooperación administrativa", Revista d'estudis autonòmics i federals, 31, 2020, 17-64; M. Pérez Gabaldón, Los problemas competenciales en materia medioambiental y las relaciones intergubernamentales como posible vía de solución, Valencia, 2011, 24 ss. 


\section{LAS DINÁMICAS RELACIONALES INTERGUBERNAMENTALES EN MATERIA AMBIENTAL: UN EXAMEN CUANTITATIVO Y CUALITATIVO}

Los distintos tipos de instrumentos de colaboración entre centro y periferia empleados a lo largo de los años pueden ser adscritos a sistemas bilaterales y multilateral. Éstos pueden ser: i) Funcionales a la realización de la descentralización, como las comisiones mixtas de transferencia de recursos, funciones y servicios de la Administración del Estado a las distintas Comunidades Autónomas y que, por ende, llevan a cabo la descentralización de las atribuciones; ii) Órganos consultivos o funcionales a la preparación del trabajo de otros órganos y administraciones ("órganos colegiados de la Administración General del Estado en los que participan las Comunidades Autónomas"), como el Consejo Nacional del Agua, el Consejo Nacional del Clima, el Consejo de la Red de Parques Nacionales o el Consejo Nacional de Bosques ${ }^{18}$; iii) Instrumentos funcionales a la operatividad financiera, técnica y administrativa de la descentralización, como el caso de los Convenios (infra); iv) Instrumentos que tienen como finalidad buscar una síntesis de intereses compartidos y la concertación sobre el ejercicio de las correspondientes competencias o la composición de los conflictos (Conferencia de Presidentes, Conferencias sectoriales y Comisiones bilaterales, infra).

A estas últimas dos categorías se dedicará el siguiente análisis, por dos órdenes de motivos.

En primer lugar, en la medida en que el estudio de estos instrumentos permite medir el grado efectivo de cooperación existente entre Estado y Comunidades Autónomas en el despliegue de sus relaciones competenciales, de esta manera, podrá ser comprobada la relación entre la estructuración constitucional inicial, la evolución

\footnotetext{
18 Sobre estos órganos vid:: M. A. Fernández- J. A. Ramos Gallarín, "El marco de las relaciones intergubernamentales de la política de medio ambiente en el Estado autonómico", en GAPP, núm. 28/29, 2004, pp. 87-104; Zambonino Pulito, "La articulación de la gobernanza multinivel a través de técnicas orgánicas de colaboración, cooperación y coordinación”, cit., p. 246 ss.
} 
institucional en el ámbito de la negociación de las partes y la actividad del Tribunal Constitucional.

En segundo lugar, en consideración que estas herramientas adquieren la condición de foros de diálogo por los que "transitan" las cuestiones cualitativamente más relevantes para la política ambiental respecto del ejercicio de las competencias. Por las razones expuestas, se procede a continuación a su estudio pormenorizado.

Se dejará a un lado la Conferencia de Presidentes, (órgano de cooperación multinivel de más alto nivel político integrada por el Presidente del Gobierno de la Nación y por los 17 Presidentes de las Comunidades Autónomas) ${ }^{19}$, dado que su ámbito de actuación abarca las cuestiones políticas de común interés más destacadas que no han afectado a lo largo del tiempo y hasta la fecha a la materia ambiental. Sin embargo, en nuestra opinión, se trata de una oportunidad perdida para los propósitos de cooperación en materia ambiental. En efecto, muchos asuntos ambientales caracterizados por un alto perfil político y estratégico ${ }^{20}$ o por intereses contrastados ${ }^{21}$ podrían ser reconducidos y discutidos en la Conferencias

\footnotetext{
${ }^{19}$ Se constituyó el 28 de octubre de 2004, accesible en <https://www.mptfp.gob.es/portal/politicaterritorial/autonomica/coop autonomica/Confer Presidentes.html> [Último acceso: 28.7.2020], y fue creada por el art. 146 de la Ley 40/2015. Vid.: R. Bocanegra Sierra- A. Huergo Lora, La Conferencia de Presidentes, lustel. Madrid, 2005; L. A. Gálvez Muñoz- J. G. Ruiz González, "Estado autonómico, cooperación intergubernamental y Conferencias de Presidentes", en Revista de Derecho Político, núm. 86, 2013, p. 239 ss.; E. Aja, "La Conferencia de Presidentes del Estado autonómico", en Informe Comunidades Autónomas, Barcelona: Instituto de Derecho Público, 2005, pp. 791-801.

${ }^{20}$ Un ejemplo se refleja en las cuestiones relacionadas con el agua. Cómo informa M. Pérez Gabaldón (en Los problemas competenciales en materia medioambiental y las relaciones intergubernamentales como posible vía de solución, cit., 153): "Murcia y Comunidad Valenciana han aludido continuamente a la necesidad de convocar una reunión de la Conferencia de Presidentes para hablar específicamente temas relativos al recurso hídrico. El jueves 7 de enero de 2010 el Conseller de Medio Ambiente, Agua, Urbanismo y Vivienda de la Comunidad Valenciana, Juan Cotino, acordó en el pleno de Les Corts solicitar al Presidente del Gobierno Nacional que convocase una Conferencia de Presidentes Autonómicos para que "se aborde en profundidad la problemática del agua de todo el territorio nacional, ya que fue un punto no debatido en las dos últimas conferencias" y con el fin de que pueda "alcanzarse un acuerdo de Estado que tenga como eje el Plan Hidrológico Nacional (PHN) de 2001”. Así, el 11 de enero de 2010, los Presidentes de Murcia y Comunidad Valenciana reclamaron al Presidente Rodríguez Zapatero la urgente necesidad de tal convocatoria."

${ }^{21}$ Un ejemplo de ello es el caso emblemático de la fractura hidráulica que ha dado lugar a la aprobación, por parte de algunas Comunidades Autónomas, de leyes dirigidas a su prohibición que ha suscitado la oposición del Estado, acabando el conflicto ante el Tribunal Constitucional en seis ocasiones. Vid. las Sentencias 106/2014 (Cantabria), 134/2014 (La Rioja); 208/2014 (Comunidad Foral de Navarra); 73/2016 (Cataluña); 8/2018 (País Vasco); 65/2018 (Castilla-La Mancha).
} 
de Presidentes, en un intento de evitar que deriven finalmente en recursos y conflictos ante el Tribunal Constitucional.

Por lo tanto, el núcleo de la cooperación multinivel formalizada ${ }^{22}$ entre Estado y Comunidades Autónomas, que se analizará en los siguientes apartados, es representado, en primer lugar, por las Conferencias sectoriales ${ }^{23}$, en las que participan el ministro competente por razón de materia y un consejero por cada Comunidad. Entre las 45 Conferencias sectoriales ${ }^{24}$ instituidas hasta la fecha, se dedicará el apartado núm. 1 a la Conferencia Sectorial de Medio Ambiente, come foro principal de la cooperación multinivel en materia ambiental ${ }^{25}$.

En segundo lugar, las Comisiones bilaterales ${ }^{26}$ integradas por los miembros del Gobierno estatal y autonómico se analizarán específicamente en el siguiente párrafo (núm. 2).

\section{La Conferencia sectorial de medio ambiente}

${ }^{22}$ Sobre esta cuestión, vid.: C. Colino Cámara, "Las relaciones intergubernamentales en España", en J. Tudela Aranda-F. Knüpling, (dir.), España y modelos de federalismo, Fundación Giménez Abad de Estudios Parlamentarios y del Estado Autonómico-Centro de Estudios Políticos y Constitucionales. Madrid, 2010; Ridaura Martínez, Relaciones intergubernamentales: EstadoComunidades Autónomas, cit.; J. M. Pérez Medina, "Las relaciones de colaboración entre el Estado y las Comunidades Autónomas, desde la perspectiva de la Administración General del Estado", en Revista Jurídica de Castilla y León, núm. 19, 2009, p. 326 ss.

${ }^{23}$ La nueva ley 40/2015, de Régimen Jurídico del Sector Público, regula las Conferencias sectoriales en los arts. 147-152, de esta manera sustituyendo y ampliando la anterior regulación del art. 5 de la ley 30/1992 y y por el art. 4 de la ley 12/1983. Sobre las Conferencias sectoriales vid.: J. Tajadura Tejada, "Federalismo cooperativo y Conferencias Sectoriales: Marco normativo y propuestas de reforma", en Revista Jurídica de Navarra, núm. 49, 2010; J. C. Duque Villanueva, "Las Conferencias Sectoriales", en Revista Española de Derecho Constitucional, 79, 2007; J. Tornos Mas, "Las Conferencias Sectoriales", en Documentación Administrativa, núm. 240, 1994; G. Fernández Farreres, "Las conferencias sectoriales y los consorcios en las relaciones de colaboración entre el Estado y las Comunidades Autónomas", en Las relaciones interadministrativas de cooperación y colaboración, Institut d'Estudis Autonòmics. Barcelona, 1993, pp. 115-168.

24 Información actualizada al 31/12/2018. Vid. la página web del Ministerio de Política Territorial y Función Pública, accesible en <https://www.mptfp.gob.es/portal/politicaterritorial/autonomica/coop autonomica/Conf Sectoriales.html>[Último acceso: 28.7.2020].

${ }^{25}$ En cambio, se omitirá la Conferencia Sectorial del Agua ya que es la única Conferencia que no ha llegado a constituirse formalmente y sus miembros nunca han llegado a reunirse.

26 Vid.: I. Aragonés Seijo, "El principio de bilateralidad en la reforma de los Estatutos de Autonomía", en Institut de Dret Públic Working Papers, núm. 1, 2012, pp. 1-55; E. R. Molés, "Contenido y eficacia de los acuerdos de las Comisiones bilaterales en el procedimiento del artículo 33.2 LOTC", Estudios monograficos, Informe Comunidades Autónomas, 2015, 39-70; M. J. Ridaura Martínez, "Las comisiones bilaterales de cooperación en el sistema autonómico español", en Cuadernos constitucionales de la Cátedra Fadrique Furió Ceriol, 60/61, 2007, pp. 65-84. 
La Conferencia Sectorial de Medio Ambiente fue una de las primeras en constituirse, en noviembre de 1988. Está adscrita al Ministerio para la Transición Ecológica y el Reto Demográfico y está asistida por el Consejo consultivo de política ambiental para los asuntos comunitarios que, desde 2001, se encarga de las cuestiones inherentes a la participación en los asuntos europeos, y por algunos grupos de trabajo temáticos (por ejemplo, la Reunión de Directores generales de agua, la Reunión de directores generales de calidad y evaluación ambiental, la Comisión nacional para conservación de la naturaleza, el Comité de lucha contra los incendios Forestales, la Comisión de coordinación de residuos).

La Conferencia Sectorial de Medio Ambiente (el pleno) se reúne al menos dos veces al año (art. 9 Reglamento Interno) ${ }^{27}$ y la convocatoria y el orden del día de las reuniones se determinan por la Presidencia, que recae en la persona titular del Ministerio (art. 12 Regl.). Previamente a la sesión de la Conferencia se reúne la Comisión Sectorial del Medio Ambiente, convocada por la persona titular de la Secretaría de Estado de Cambio Climático, de la Secretaría de Estado de Medio Rural y Agua, de la Secretaría General de Medio Rural o de la Secretaría General del Mar, en función de los temas que se prevea incluir en el orden del día (art. 10 Regl.). Las Comunidades Autónomas pueden proponer la inclusión de puntos en el orden del día ${ }^{28}$.

La Conferencia Sectorial de Medio Ambiente desarrolla funciones de representación y discusión de proyectos de ley estatal que afectan a las competencias autonómicas; de redacción y actuación de planes y programas conjuntos entre Estado y Comunidades en cuanto tengan que ser alcanzados objetivos comunes y ejercidas las correspondientes competencias; de distribución territorial de

\footnotetext{
27 Vid. Reglamento de la Conferencia Sectorial de Medio Ambiente, aprobado en la reunión de 29 de julio de 2009.

${ }^{28}$ Para profundizar cómo funciona la Conferencia en la práctica (tanto en pleno, como en comisiones, grupo de trabajo y el Consejo Consultivo de la misma) nos remitimos a: J. Mondragón Ruiz de Lezana et Al., Análisis de las conferencias sectoriales (2001-2012): valores y percepciones de los agentes políticos y técnicos y dinámica de funcionamiento, Instituto Nacional de Administración Pública. Madrid, 2015.
} 
subvenciones estatales; de intercambio continuado de informaciones ambientales entre la Administración del Estado y las distintas Comunidades Autónomas; además de estas funciones, cualquier otra que les pueda ser encomendada por la legislación sectorial ambiental ${ }^{29}$.

Por último, entre los instrumentos de los que pueden disponer las Conferencias sectoriales para llevar a cabo estas actividades y decisiones se prevén: acuerdos ${ }^{30}$, recomendaciones ${ }^{31}$, planes y programas conjuntos para comprometer actuaciones conjuntas para la consecución de los objetivos comunes ${ }^{32}$ y convenios de colaboración ${ }^{33}$.

Teniendo en cuenta estas informaciones sintéticas sobre la composición, las reuniones, las funciones y los instrumentos que el legislador atribuye a la Conferencia Sectorial de Medio Ambiente, con la finalidad de entender su papel efectivo en la articulación de las relaciones entre Estado y Comunidades, es preciso analizar algunos datos.

Primeramente, debe observarse que - frente a las 66 reuniones mantenidas desde su creación en noviembre de 1988 hasta $2018^{34}$, a las cuales se suman 36

29 Por ejemplo, vid. los artículos 1.2 y 4 de la Ley 21/2013, de 9 de diciembre, de evaluación ambiental.

30 La forma del acuerdo se prevé por la Ley 40/2015 en los siguientes artículos: 146 para la Conferencia de los Presidentes, 151 para las Conferencias sectoriales, 153 para las Comisiones bilaterales, 154 para las Comisiones territoriales de coordinación. Sobre la obligatoriedad de los acuerdos vid:: Zambonino Pulito, "La articulación de la gobernanza multinivel a través de técnicas orgánicas de colaboración, cooperación y coordinación”, cit., 242-243.

31 Vid. art. 151 de la Ley 40/2015.

${ }^{32}$ Art. 7 de la Ley 30/1992, modificado por la ley 4/1999, posteriormente art. 148 de la ley 40/2015. Para profundizar nos remitimos a: M. Alda Fernández, Los planes y programas conjuntos como instrumentos de cooperación intergubernamental: características y evolución en el Estado Autonómico, Congreso CLAD, Madrid, 2004.

${ }_{33}$ Art. 6 de la ley 30/1992, modificado por la ley 4/1999, posteriormente art. 143 de la Ley 40/2015. Sobre el tema vid:: M. J. García Morales, "Relaciones de colaboración con las Comunidades Autùnomas", en Informe Comunidades Autónomas, 2005, pp. 72-95; E. Albertí Rovira, "El régimen de los convenios de colaboración entre administraciones: un problema pendiente", en Informe Comunidades Autónomas, 1996; L. López Nieto, Interdependencia functional en un context de autonomía política: los convenios de colaboración entre el gobierno nacional y las Comunidades Autónomas en el Sistema español de relaciones intergubernamentales, Congreso CLAD, Madrid, 2004.

${ }^{34}$ En particular: 4 reuniones han sido celebradas en el período 1988-1991, 40 en los años 19922009, 22 en los años 2010-2018. Vid.: Dirección General de Cooperación Autonómica y Local, Informe sobre la actividad de las Conferencias Sectoriales en 2018, Ministerio de Política Territorial y Función Pública, Madrid, 2019, accesible en <https://www.mptfp.gob.es/portal/politica- 
reuniones del Consejo consultivo de política medioambiental para asuntos comunitarios - han sido muy reducidos, en términos generales, los acuerdos suscritos $^{35}$ entre las partes como resultado de las negociaciones en materia de proyectos normativos $\mathrm{u}$ otros actos con fuerza de ley.

Como puede verse en las figuras siguientes (figura 1 y 2 ), en relación con el número total de actividades realizadas en las reuniones de la Conferencia Sectorial de Medio Ambiente celebradas entre los años 2001-201836, las actividades de discusión y aprobación de proyectos normativos del Estado ocupan una dimensión muy reducida, que se reduce ulteriormente entre los años 2013-201837.

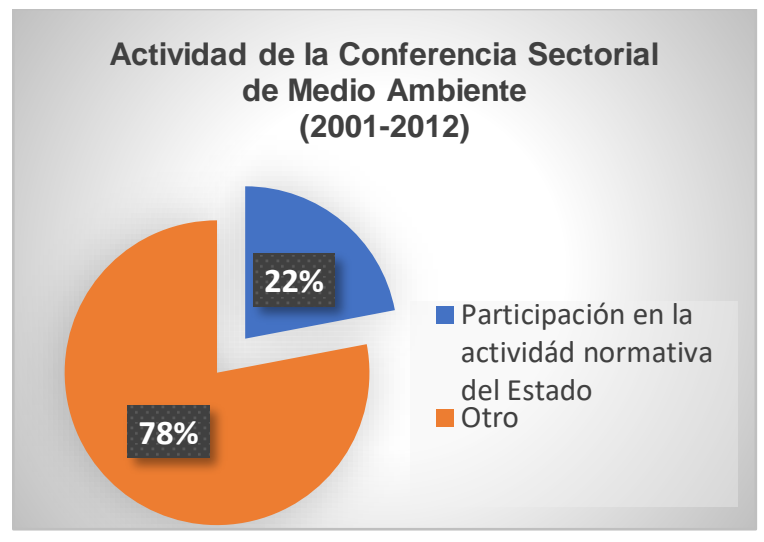

Figura 1 (Fuente: elaboración propia) ${ }^{38}$ : Participación de las Comunidades Autónomas en la Actividad normativa del Estado en la Conferencia Sectorial de Medio Ambiente (2001-2012).

territorial/autonomica/coop autonomica/Conf Sectoriales/Conf Sect Reuniones.html> [Último acceso: 28.7.2020].

${ }^{35}$ Así lo destaca: J. G. Ruiz González, "La cooperación intergubernamental en el estado autonómico: situación y perspectivas", Revista de Estudis Autonòmics i Federals, núm. 15, 2012, p. 297. Vid. Informes anuales sobre la actividad de las Conferencias Sectoriales, accesible en $<$ https://www.mptfp.gob.es/portal/politica-

territorial/autonomica/coop autonomica/Conf Sectoriales/Conf Sect Reuniones.html> [Último acceso: 28.7.2020].

${ }^{36}$ Computadas sobre las bases de los órdenes del día de las reuniones publicados en los informes anuales de las Conferencias sectoriales

${ }^{37}$ En el Informe de 2018 ha sido computada por separado la actividad de los órganos de apoyo de la Conferencia sectorial de Medio Ambiente que suman aproximadamente 30, de las cuales aproximadamente 8 con el objeto de presentar, discutir y/o aprobar de los proyectos normativos del Estado. Estas actividades no se han incluido en la figura.

${ }^{38}$ Elaboración de los datos contenidos en los informes anuales de la Conferencia sectorial de Medio Ambiente, 


\section{Actividad de la Conferencia Sectorial de Medio Ambiente} (2013-2018)
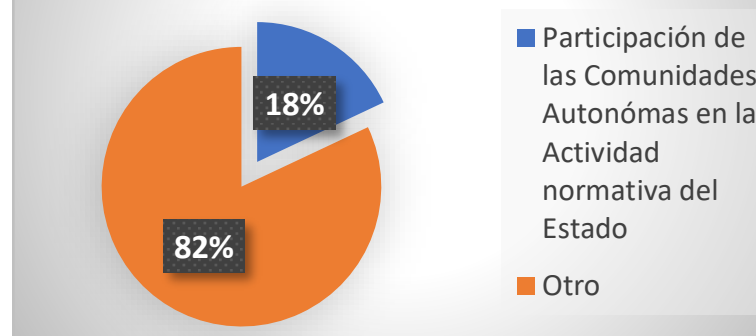

Figura 2 (Fuente: elaboración propia) ${ }^{39}$ : Participación de las Comunidades Autónomas en la Actividad normativa del Estado en la Conferencia sectorial de Medio Ambiente (2013-2018)

El reducido número de proyectos normativos discutidos no pasó desapercibido tampoco para el Ministerio de Política Territorial y Función Pública, que, en el Informe de 2018 sobre la actividad de las Conferencias sectoriales, observado el escaso uso de este instrumento de cooperación, auspició que "la función de participación autonómica en la elaboración de los proyectos normativos del Estado, debería convertirse en un mecanismo de prevención de posibles conflictos competenciales", sobre todo a la luz de la consideración de que "durante la recientemente finalizada XII Legislatura las Comunidades Autónomas han interpuesto 14 recursos de inconstitucionalidad contra leyes dictadas por el Estado y 4 conflictos de competencia. Estos mismos datos correspondientes a la $\mathrm{X}$ Legislatura (2011-2015) son de 115 recursos y 21 conflictos de competencia, un número significativamente mayor pero que en todo caso pone de relieve la necesidad de abordar este problema de forma preventiva en régimen de cooperación"40.

territorial/autonomica/coop autonomica/Conf Sectoriales/Conf Sect anuales.html>

[última consulta el 25.7.2020].

39 Vid. supra.

40 Dirección General de Cooperación Autonómica y Local, Informe sobre la actividad de las Conferencias Sectoriales, Ministerio de Política Territorial y Función Pública, Madrid, 2018, p. 31. 
También el contenido de los acuerdos suscritos confirma la relevancia de las Conferencias sectoriales. En particular, la lectura de los Informes anuales sobre la actividad de las Conferencias sectoriales, revela que la Conferencia Sectorial de Medio Ambiente ha aprobado desde su constitución hasta la fecha sobre todo acuerdos acerca de la distribución de subvenciones del Estado a las Comunidades Autónomas en materia de medio ambiente en la que éstas ejercen competencias propias, así como acuerdos de trasferencia de fondos para la gestión o la ejecución de medidas, planes ${ }^{41}$, actuaciones ambientales que proceden generalmente de obligaciones comunitarias ${ }^{42}$. En cambio, son escasos los acuerdos sobre proyectos normativos básicos cuando corresponde a las Comunidades Autónomas su desarrollo o ejecución ${ }^{43}$.

Por lo tanto, aunque a la Conferencia Sectorial de Medio Ambiente se le reconozca, sobre el pape ${ }^{44}$, una función importante para la cooperación entre Estado y Comunidades en la elaboración y adopción de proyectos normativos, especialmente si estos pueden afectar en las esferas competenciales autonómicas, lo cierto es que, en la práctica, este rol se ejerce en medida menor y esencialmente residual, respecto de las demás funciones.

En general, la doctrina considera que los resultados mediocres de las Conferencias sectoriales en referencia a las participación autonómica en la elaboración y en la adopción de proyectos normativos se deben a distintas razones: la falta de una cultura del federalismo cooperativo en España; la desconfianza de las Comunidades Autónomas hacia el centralismo estatal; la competencia entre Estado y Comunidades Autónomas (o, al menos, algunas de ellas) por establecer esferas de poder más amplias posible; el temor de las administraciones a perder sus

\footnotetext{
${ }^{41}$ Por ejemplo, más recientemente, ha sido aprobado el "Plan Integrado de Enegía y Clima 2018".

42 Desde 2001 las cuestiones ambientales derivadas de la política ambiental de UE se discuten separadamente por el Consejo Consultivo de Política Medioambiental para Asuntos Comunitarios.

43 Vid.: Dirección General de Cooperación Autonómica y Local, Informe sobre la actividad de las Conferencias Sectoriales, Ministerio de Política Territorial y Función Pública, Madrid (2009-2018).

${ }^{44}$ Art. 148.2 apartado a) de la ley 40/2015: "En particular, las Conferencias Sectoriales ejercerán, entre otras, las siguientes funciones: a) Ser informadas sobre los anteproyectos de leyes y los proyectos de reglamentos del Gobierno de la Nación o de los Consejos de Gobierno de las Comunidades Autónomas cuando afecten de manera directa al ámbito competencial de las otras Administraciones Públicas o cuando así esté previsto en la normativa sectorial aplicable, bien a través de su pleno o bien a través de la comisión o el grupo de trabajo mandatado al efecto".
} 
competencias; la reticencia por nacionalismo de algunas Comunidades a cooperar en un marco multilateral para obtener un status diferenciado; y, finalmente, la preferencia generalizada por la negociación bilateral en lugar de multilateral, considerada más apta para la satisfacción del interés específico de cada Comunidad ${ }^{45}$.

En este sentido, un estudio empírico ${ }^{46}$ ha evidenciado algunos interesantes aspectos acerca de las modalidades de participación del Gobierno da la Nación y de las Comunidades Autónomas en las Conferencias sectoriales, tomando en consideración tres Conferencias en particular, entre las cuales la de Medio Ambiente. Los resultados de la investigación, que tiene como objeto la actividad de las Conferencias en los años 2001-2012, resaltan la tendencia de las Comunidades (sobre todo algunas) ${ }^{47}$ a preferir otras fórmulas de cooperación, como las Comisiones bilaterales, que garantizan de forma mayor la asimetría autonómica y la tutela de las prerrogativas propias de cada Comunidad Autónoma.

Tal como subraya el estudio, esta posición debe leerse también a la luz de otros elementos, por ejemplo, el poder fáctico preponderante del Gobierno del Estado en la fijación del orden del día de las reuniones (en el 92\% de los casos), en el planteamiento de las cuestiones a tratar y en la capacidad de lograr la aprobación sin una votación formal de las posiciones promovidas por el propio gobierno central, así como la caracterización política de los representantes del Gobierno de la Nación y de las distintas Comunidades que se refleja en el nivel de participación y de conflictividad en el interior de la Conferencia ${ }^{48}$.

\footnotetext{
${ }^{45}$ Ex multis, M. A. Abellán López, "Un balance de la modernización autonómica y las tensiones intergubernamentales", en Cuadernos de Gobierno y Administración Pública, núm. 2, 2, 2015, pp.165-185; E. Aja, Estado autonómico y reforma federal, Alianza. Madrid, 2014; Máiz Suárez, R., Beramendi Álvarez, P., M. Grau Creus, "La federalización del Estado de las Autonomías: evolución y déficit institucionales", en Subirats Humet, J. y Gallego Calderón, R. (coords.), Veinte años de autonomías en España: leyes, políticas públicas, instituciones y opinión pública, CIS. Madrid, 2002; J. Romero González, "El Gobierno del territorio en España. Balance de iniciativas de coordinación y cooperación territorial", en Boletín de la AGE, 39, 2005, 59-86.

46 J. Mondragón Ruiz de Lezana et Al., Análisis de las conferencias sectoriales (2001-2012): valores y percepciones de los agentes políticos y técnicos y dinámica de funcionamiento, cit.

${ }^{47}$ Por ejemplo, Cataluña y País Vasco. Vid.: Mondragón Ruiz de Lezana et Al., cit. supra.

${ }^{48}$ Como advierte J. Mondragón Ruiz de Lezana et Al. (en Análisis de las conferencias sectoriales (2001-2012): valores y percepciones de los agentes políticos y técnicos y dinámica de funcionamiento, cit., 79-80): "Otro aspecto criticado sobre la toma de decisiones es el hecho de que
} 
Por último, la Conferencia Sectorial de Medio Ambiente actúa también como órgano de coordinación de las administraciones y, por este motivo, parece el lugar menos idóneo para la cooperación paritaria entre Estado y Comunidades ${ }^{49}$.

En efecto, la coordinación de las administraciones aún implica el ejercicio de un poder jerárquico por parte del Estado que no se concilia con la relación voluntaria, inter pares, que se establece en el debate político y en el ejercicio de competencias ambientales compartidas ${ }^{50}$.

los consejeros de las Comunidades Autónomas adoptan una posición sobre los temas que se debaten en función de las consignas del partido político al que pertenecen, más que en función de los intereses de su autonomía. [...] Una de las consecuencias de que las posiciones frente a los temas se determinen en función del color político es que limita el debate y desnaturaliza el funcionamiento de las Conferencias". Puede consultarse también Id., "Entre el liderazgo y la institucionalización: un estudio de caso de las Conferencias Sectoriales de salud, educación y medio ambiente". In Sociedades en constante cambio: realidad social y reto científico: actas del X Congreso vasco de sociología y ciencia política, Universidad del País Vasco/Euskal Herriko Unibertsitatea, 2018, pp. 575-597.

${ }^{49}$ En el mismo sentido J. M. Pérez Medina (en "Dinámica de las conferencias sectoriales. Entre la intergubernamentalidad y la cooperación administrativa", cit., p. 32-33): "Por un lado, las conferencias son órganos intergubernamentales, de deliberación política, y en su caso de decisión conjunta para hacer efectiva la participación y la codecisión sobre problemas comunes. Pero, por otro lado, son órganos interadministrativos, que culminan la estructura piramidal de órganos ordenados a diferentes niveles [...] La tendencia federalista tiende a resaltar el primero de estos papeles, pero la Administración del Estado y la propia práctica insisten en explorar sus posibilidades incluso como instrumento de coordinación administrativa, en línea con lo ya establecido por el Tribunal Constitucional, cuando en la Sentencia 76/1983, de 5 de agosto, recaída sobre la Ley Orgánica del Proceso Autonómico (LOAPA), apuntó que "en caso de ejercer el Estado la competencia de coordinación en el marco de una conferencia sectorial, el alcance del acuerdo adoptado será lógicamente el que se derive del ejercicio de la competencia de coordinación" (FJ. 13). Sin embargo, este carácter bifronte de las Conferencias no encaja de forma plenamente satisfactoria en una norma administrativa como es la actual Ley de Régimen Jurídico del Sector Público."

50 Vid.: STC 194/2004 (FJ 9): "En este sentido, en nuestra doctrina hemos conectado la cooperación con la idea de la voluntariedad y la coordinación con la de la imposición". También vid. STC 32/1983, 104/1988, 27/1987, 227/1988, 214/1989, 118/1996 y 101/2005. Sin embargo, se ha apartado de esta doctrina la STC 31/2010 que ha afirmado la superioridad del Estado sobre las Comunidades Autónomas: "Dicha relación, amén de no ser excluyente de la multilateralidad, como el propio precepto impugnado reconoce, no cabe entenderla como expresiva de una relación entre entes políticos en situación de igualdad, capaces de negociar entre sí en tal condición, pues, como este Tribunal ha constatado desde sus primeros pronunciamientos, el Estado siempre ostenta una posición de superioridad respecto de las Comunidades Autónomas (STC 4/1981, FJ 3). De acuerdo con ello el principio de bilateralidad sólo puede proyectarse en el ámbito de las relaciones entre órganos como una manifestación del principio general de cooperación, implícito en nuestra organización territorial del Estado." (FJ 13). 
En definitiva, ante la existencia de múltiples factores que explican los resultados no satisfactorios de las Conferencias, parece claro que la deficiencia de su diseño institucional no ha facilitado su funcionamiento.

Otro estudio empírico ${ }^{51}$, anterior pero que en su análisis abarca un período más amplio de actividades de las Conferencias sectoriales al incluir su fase inicial de actividad (de finales de los ochenta - principios de los noventa del pasado siglo), ha evidenciado las mismas dinámicas intergubernamentales y ha destacado la importancia de estos órganos especialmente en lo que concierne al desarrollo compartido de funciones administrativas y financieras propias de distintos niveles de gobierno. Dicha función ha resultado ser preferente sobre aquella de cooperación normativa y de prevención de potenciales conflictos competenciales, así como de discusión de intervenciones legislativas que afectaran a las correspondientes competencias (también ambientales) compartidas entre Estado y Comunidades. Estas observaciones parecen confirmadas también por el abundante número de convenios $^{52}$ suscritos tanto por la Conferencia sectorial, como en sede bilateral entre el Ministerio y la Comunidad.

En efecto, aunque los convenios deberían más propiamente considerarse como instrumentos de cooperación bilateral, en la práctica, "constituyen el instrumento de cooperación de uso más frecuente en el Estado Autonómico por la libertad contractual característica de esta figura, que le otorga una especial idoneidad y flexibilidad", por lo que han sido empleados por el Gobierno del Estado también para alcanzar convenios multilaterales con varias o todas las Comunidades Autónomas; así que se hace referencia a ellos como "convenios de suscripción generalizada, proponiendo el mismo, o parecido texto, a todas o una gran parte de las Comunidades Autónomas" 33 .

51 X. Arbós Marín (coord.), Las relaciones intergubernamentales en el estado autonómico: La posición de los actores, Colección Institut d'Estudis Autonómics. Barcelona, 64, 2009.

${ }^{52}$ Regulados por la Ley 40/2015 de Régimen Jurídico del Sector Público y dal Orden PRA/1267/2017.

${ }_{53}$ Ministerio de Política Territorial y Función Pública, Informe sobre los convenios de cooperación Estado-Comunidades Autónomas suscritos, (1981-2020). Un comentario de estos convenios puede verse en: M. A. Fernández - J. A. Ramos Gallarín, "El marco de las relaciones intergubernamentales de la política de medio ambiente en el Estado autonómico", en GAPP, 28/29, 2003-2004, pp. 98-99; 
En materia ambiental, se han suscrito cientos de convenios desde 1981, con un contenido variable, pero atribuible a los siguientes tipos: la adopción de acciones conjuntas para la implementación de planes y programas, el establecimiento de consorcios, la gestión de obligaciones administrativas, la asignación de recursos para la implementación de medidas y funciones ejecutivas en materias compartidas ${ }^{54}$.

El siguiente gráfico (Gráfico 1), muestra el uso de convenios a lo largo de los años 55: se observa el incremento exponencial de los convenios (columnas azules) que alcanzan aproximadamente el número de 1000 en la década 2001-2010, para luego asentarse en unos 600-700 en los años posteriores. Junto a estos convenios que conciernen a todos los sectores de las políticas públicas, las columnas naranjas muestran la tendencia de los convenios suscritos en materia ambiental, que aumenta en el bienio 1994-1995, pasando de menos de una decena en la década anterior a alrededor de cincuenta; en la década 2005-2015 oscilan entre 30 y 80 , para luego situarse en 15-25 en los años posteriores.

J. Tajadura Tejada, El principio de cooperación en el Estado Autonómico, Editorial Comares, 3ª Ed., 2010.

54 Vid.: M. J. García Morales, "Relaciones de colaboración con las Comunidades Autónomas", Informe Comunidades Autónomas, 2006, 72-95.

${ }^{55}$ Los convenios suscritos entre Estado y Comunidades Autónomas son los seguientes: 1980 (Tot. 9, Amb 0), 1981 (Tot 20, Amb. 9), 1982 (Tot. 25, Amb. 0), 1983 (Tot. 54, Amb. 0), 1984 (Tot. 117, Amb. 1), 1985 (Tot. 118, Amb. 13), 1986 (Tot. 107, Amb. 5), 1987 (Tot. 161, Amb. 15), 1988 (Tot. 165, Amb. 2), 1989 (Tot. 244, Amb. 7), 1990 (Tot. 231 Amb. 2), 1991 (Tot. 234 Amb. 4), 1992 (Tot. 312 Amb. 12), 1993 (Tot. 293, Amb. 18), 1994 (Tot. 343, Amb. 36), 1995 (Tot. 369, Amb. 54), 1996 (Tot. 352, Amb. 4), 1997 (Tot. 520, Amb. 7), 1998 (Tot. 493, Amb. 10), 1999 (Tot. 752, Amb. 12), 2000 (Tot. 730, Amb. 14), 2001 (Tot. 863, Amb. 29), 2002 (Tot. 1060, Amb. 33), 2003 (Tot. 952, Amb. 12), 2004 (Tot. 747, Amb. 32), 2005 (Tot. 911, Amb. 60), 2006 (Tot. 1083, Amb. 69), 2007 (Tot. 1093, Amb. 47), 2008 (Tot. 1001, Amb. 43), 2009 (Tot. 1059, Amb. 82), 2010 (Tot. 1009, Amb. 65), 2011 (Tot. 678, Amb. 67), 2012 (Tot. 349, Amb. 24), 2013 (Tot. 549, Amb. 49), 2014 (Tot. 610, Amb. 48), 2015 (Tot. 665, Amb. 44), 2016 (Tot. 488, Amb. 23), 2017 (Tot. 593, Amb. 25), 2018 (Tot. 603, Amb. 20), 2019 (Tot. 648, Amb. 15). Para acceder a los informes véase: Ministerio de Política Territorial y Función Pública (1980-2019), Informes anuales sobre los convenios de cooperación Estado Comunidades Autónomas. 


\section{Convenios suscritos entre 1981-2019}

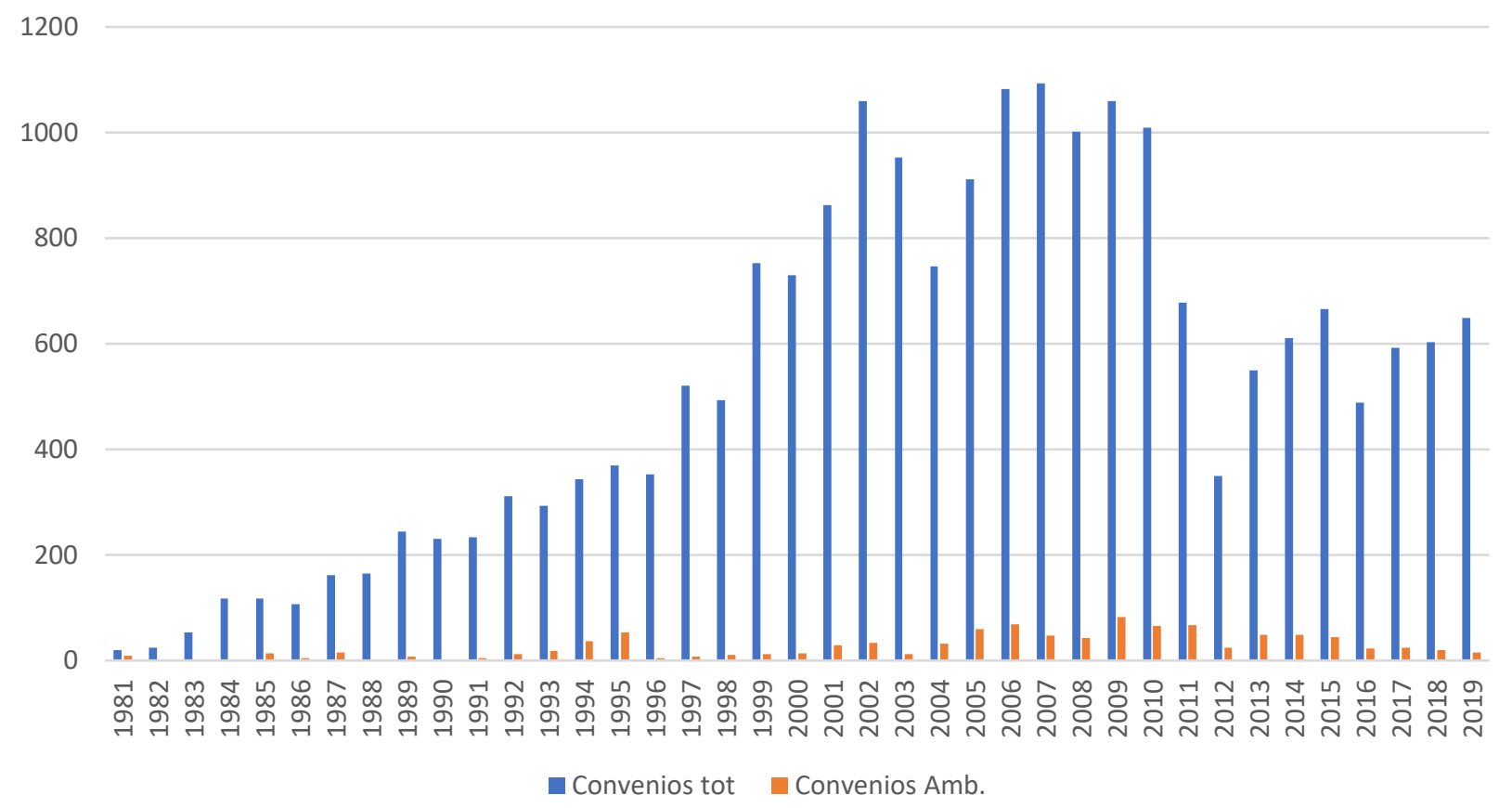

Gráfico 1 (Fuente: elaboración propia) ${ }^{56}$ : Convenios suscritos durante 1981-2019

A partir de los inicios de los años 2000, casi el $50-70 \%$ de los convenios son de suscripción generalizada, por este motivo, aunque suscritos formalmente con cada Comunidad corresponden en el fondo a una fórmula de cooperación vertical multilateral y son empleados por el Estado para uniformar la acción administrativa sobre territorio (como afirma el propio Ministerio de Administraciones Públicas: "aportan una perspectiva homogénea en las relaciones de colaboración dentro del Estado autonómico") ${ }^{57}$ y para transferir recursos financieros a las administraciones autonómicas funcionales a la implementación de políticas públicas a nivel descentralizado. La participación de las Comunidades en la suscripción de los convenios varía, sin embargo, notablemente incluso a lo largo de los años. Por

\footnotetext{
${ }^{56}$ Elaboración de los datos contenidos en los Informes anuales sobre los convenios de colaboración Estado-Comunidades Autónomas suscritos durante el 1980-2019. Para acceder a los informes véase Ministerio de Política Territorial y Función Pública: <http://www.mptfp.es/portal/politicaterritorial/autonomica/coop autonomica/Convenios Colaboracion.html> [Último acceso: 28.7.2020]. 57 Vid. Informe sobre los convenios de colaboración Estado-Comunidades Autónomas suscritos durante el 2007, 11.
} 
ejemplo, entre 1998 y 2005 acerca del $30 \%$ de los convenios en materia de medio ambiente ha sido suscrito por las Comunidades de Cataluña y de la Galicia, mientre entre 2006-2019 el porcentaje referido a Cataluña (23 convenios) baja a casi el 4\% de los convenios ambientales totales (552) suscritos entre Estado y Comunidades Autónomas.

En conclusión, sobre la base de la investigación realizada por otros estudiosos y los datos aquí recogidos y analizados, las Conferencias sectoriales y, especialmente, la Conferencia ambiental, parecerían funcionar eficazmente como organismos multiniveles y multilaterales para llevar a cabo actividades operativas de las distintas Administraciones, para financiar las acciones de descentralización territorial, para intercambiar la información necesaria a nivel nacional y para transmitir información a nivel supranacional.

De acuerdo con ello, el papel de las Conferencias es positivo en cuanto a su función de enlace entre el centro y la periferia en aquellos ámbitos en los que se puede decir que la colaboración administrativa y técnica es fisiológica para la consecución de los objetivos establecidos, así como para la transferencia de recursos del Estado a las Comunidades y, por tanto, en los casos en que no existan divergencias de objetivos, en estos supuestos se entiende, además, "dar dinero nunca es invasión de competencias" $" 58$.

Más problemática parece, en cambio, la cooperación entre Estado y Comunidades sobre la elaboración y adopción de las políticas ambientales, cuando se trata de compartir el ejercicio de las competencias normativas ${ }^{59}$, en estos supuestos, pues, las partes interactúan a partir de posturas divergentes.

${ }^{58}$ Como afirma un funcionario de las Comunidades entrevistado sobre el avance de las actividades realizadas en las Conferencias sectoriales. Vid:: Arbós Marín (coord.), Las relaciones intergubernamentales en el estado autonómico: La posición de los actores, cit., 202.

59 Un Autor observa más recientemente cómo los métodos de ejercicio del poder legislativo también afectan el funcionamiento de las Conferencias: "La proliferación de los reales decretos-leyes [...] que, por su propia naturaleza, resultan prácticamente imposibles de debatir con las Comunidades. Los datos cuantitativos son relevantes, pues en el periodo 2016-2019 el número de reales decretosleyes aprobados, 74, supera el de leyes, solo 41. Esta forma de legislar implica un menoscabo de las funciones de los órganos de cooperación, que son sustituidos en la práctica por los grupos parlamentarios y diputados o senadores nacionalistas o regionalistas, que tienen así la oportunidad de recuperar en el Congreso un margen de maniobra para influir en el sentido que interese a sus 
Por tanto, se esperaría de estas observaciones una cooperación bilateral vertical Estado-Comunidades más copiosa, especialmente para el ejercicio de las competencias normativas compartidas, donde la cooperación multinivel (multilateral) tiene límites que la hacen no preferible en la práctica.

\section{La Cooperación bilateral en materia de medio ambiente: las Comisiones bilaterales de cooperación}

La bilateralidad vertical, considerada congénita a la estructura constitucional inicial abierta a la negociación de las partes y a la dinámica propulsora de los "hechos diferenciales", se manifestó desde un principio como una dimensión preferencial respecto a los foros multilaterales, especialmente para algunas Comunidades, y sirvió para definir las líneas de diferenciación autonómica, para proteger los intereses de los territorios y para el ejercicio de las competencias compartidas ${ }^{60}$.

Las primeras Comisiones bilaterales de cooperación fueron creadas - tras el establecimiento de la Junta de Cooperación con la Comunidad de Navarra, que actuó como precursora ${ }^{61}$ - como continuación ideal de las Comisiones de Traspasos de recursos y servicios ${ }^{62}$ a las Comunidades (aunque quedan como

competencias o ciudadanos." Vid. J. M. Pérez Medina, "Dinámica de las conferencias sectoriales. Entre la intergubernamentalidad y la cooperación administrativa", Revista d'estudis autonòmics $i$ federals, 31, 2020, 53-54.

60 Vid.: J. A. Ramos, Las Comisiones Bilaterales de Cooperación en el sistema español de relaciones intergubernamentales, en L. López Nieto (Coord.): Relaciones intergubernamentales en la España democrática (interdependencia, autonomía, conflicto y cooperación), Dykinson, Madrid, 2006; J. A. Ramos, La dimension bilateral de las relaciones intergubernamentales en el Estado autonómico: las Comisiones bilaterales de cooperación, IX Congreso CLAD, Madrid, 2004; Corretja, Vintró, Bernadí, Bilateralidad y multilateralidad. La participación de la Generalitat en políticas y organismos estatales, y la Comisión Bilateral, cit.

${ }^{61}$ La Junta de Cooperación fue creada "para plantear y resolver todas las discrepancias que se suscitaran entre la Administración del Estado y la Comunidad Foral de Navarra respecto a la aplicación e interpretación de la presente Ley Orgánica de Reintegración y Amejoramiento". Vid.: Ridaura Martínez, "Las comisiones bilaterales de cooperación en el sistema autonómico español", cit., p. 66.

62 "Las Comisiones Bilaterales surgieron de forma casi natural como prolongación de las Comisiones de Traspasos, tras la realización de los primeros paquetes de transferencias, cuando el objeto de negociación no era un traspaso sino un acuerdo de otro género o el intento de evitar el conflicto". Así: E. Aja, El Estado Autonómico. Federalismo y Hechos Diferenciales, Alianza Editorial, Madrid, 2003, p. 215. 
entidades distintas) y en paralelo a las Conferencias sectoriales: es el caso de las Comisiones entre Estado y Catalunya, Galicia, País Vasco y Andalucía (1987), La Rioja y la Región de Murcia (1988), las Islas Baleares (1989), Aragón y Canarias (1990), Cantabria (1991), Castilla-León y Extremadura (1992), Asturias (1993), Castilla La Mancha (1996) y Comunidad Valenciana y Madrid (2000).

Las Comisiones bilaterales Estado-Comunidades fueron más tarde reguladas, tras el impulso de los Pactos Autonómicos de 1992, por la Ley 30/1992 como "el instrumento más efectivo para dar respuesta a las necesidades derivadas de las peculiaridades geográficas, culturales, lingüísticas o del contenido estatutario de cada Comunidad Autónoma" y de manera más amplia por la ley 4/1999 y posteriormente por la ley 40/2015, como órganos integrados por representantes de ambas administraciones "con el objeto de intercambiar información y poder llegar a acuerdos que solucionen posibles conflictos y que devengan en una pacífica aplicación de la normativa propia de cada administración, todo ello dentro de un marco de lealtad institucional".

Frente a esta primera atribución de funciones, la Ley Orgánica 1/2000 de reforma de la ley de funcionamiento del Tribunal Constitucional63 dota a las Comisiones de una importante función de resolución de disputas de carácter competencial, influyendo así en sus finalidades; de hecho, de conformidad con su art. 33.2, las Comisiones bilaterales de cooperación pueden reunirse para evitar un recurso ante el Tribunal Constitucional, por iniciativa de uno de los órganos ejecutivos (estatal o autonómico).

${ }^{63}$ En particular, la ley 1/2000 reforma el art. 33 de la ley orgánica del Tribunal Constitucional 2/1979 (LOTC). 
Por último, los Estatutos reformados ${ }^{64}$ desde 2006 dedican específicas disposiciones a las Comisiones. El Estatuto de Catalunya ${ }^{65}$, por ejemplo, establece (art. 183) la Comisión Bilateral Generalitat-Estado como el marco general y permanente de relación entre los Gobiernos de la Generalitat y el Estado con el fin de garantizar la participación y la colaboración de la Generalitat en el ejercicio de las competencias estatales que afecten a la autonomía de Catalunya y el intercambio de información y el establecimiento de mecanismos de colaboración en las respectivas políticas públicas y los asuntos de interés común.

Las funciones de la Comisión Bilateral Generalitat-Estado son deliberar, hacer propuestas y adoptar acuerdos con relación a los proyectos de ley que inciden singularmente sobre la distribución de competencias entre el Estado y la Generalitat; la programación de la política económica general; el impulso de las medidas adecuadas para mejorar la colaboración entre el Estado y la Generalitat y asegurar un ejercicio más eficaz de las competencias respectivas en los ámbitos de interés común; los conflictos competenciales planteados entre el Estado y la Generalitat; y el seguimiento de la acción exterior del Estado y de la política europea.

Para garantizar el carácter estable y permanente de la Comisión, el art. 183 prevé su reunión dos veces al año y requiere la aprobación de un reglamento interno ${ }^{66}$.

La práctica, sin embargo, no refleja la cadencia establecida por el citado reglamento interno, ya que las reuniones (9) de la Comisión se han celebrado regularmente solo

64 Vid.: art. 183 del Estatuto de Autonomía de Cataluña, art. 220 del Estatuto de Autonomía de Andalucía, art. 90 del Estatuto de Autonomía de Aragón, art. 59 del Estatuto de Autonomía de Castilla y León, art. 64 del Estatuto de Autonomía de Extremadura, art. 192 del Estatuto de Autonomía de Canarias La previsión estatutaria sobre la Comisión bilateral ha sido considerada por el Tribunal Constitucional "no contraria a la Constitución interpretada en el sentido de que no excluye otros marcos de relación, ni otorga a dicha Comisión función distinta de la de cooperación voluntaria en el ámbito de las competencias de ambos Gobiernos, que son indisponibles". STC 31/2010 (F. J. 115)

${ }^{65}$ M. Casas i Rondoní, "La Comisión Bilateral Generalitat-Estado: Regulación y actividad práctica", en Revista Catalana de Dret Públic, 42, 2011, 4 ss; M. Corretja Torrens- M. Pérez Velasco, "Cataluña", N. monografico: La colaboración en los nuevos Estatutos, Revista Jurídica de Castilla y León, 19, 2009.

${ }^{66}$ Resolución del 18/9/2007 "Acuerdo de la Comisión Bilateral Generalitat-Estado por el que se aprueba el Reglamento de dicha Comisión", posteriormente sustituido por la Resolución del 29/7/2011 "Nuevo Reglamento de la Comisión Bilateral Generalitat-Estado". El Reglamento crea las siguientes Subcomisiones: Seguimiento Normativo, Prevención y Solución de Conflictos; Colaboración y Cooperación; Infraestructuras y Equipamientos; Asuntos Europeos y Acción Exterior; Subcomisión en materia de Inmigración. 
en los primeros tres años desde la aprobación del Estatuto (2006-2009), y luego cesaron a partir de $2011^{67}$.

Un factor que sin duda ha influido en esta dirección ${ }^{68}$ ha sido la Sentencia del Tribunal Constitucional 31/2010 sobre el Estatuto catalán, que marcó una verdadera ruptura en las ya frágiles relaciones entre el Estado y la Comunidad y contribuyó al proceso de enfrentamiento institucional que culminó en el referéndum de autodeterminación convocado por el Gobierno catalán en octubre de 2017. Más recientemente, luego de un intento de relajar las relaciones entre el Estado y las Comunidades, la Comisión se reunió una vez ${ }^{69}$ en 2018 y, con el gobierno de Pedro Sánchez, se está trabajando para que tengan lugar nuevas reuniones.

Si comparamos los datos de las reuniones de las Comisiones bilaterales de otras Comunidades, a partir de la reforma de los Estatutos, la situación parece similar: la Comisión de Andalucía suma seis reuniones (2007-2011); la de Castilla y León, tres (2008-2010, la tercera en 2019); la aragonesa es la única que ha mantenido cierta continuidad (8 reuniones en los años 2008-2018), la Comisión de Comunidad Valenciana se reunió solo una vez (en 2019); en cambio, las Comisiones de otras Comunidades no han sido convocadas ${ }^{70}$.

A partir del número de reuniones registradas a lo largo de los años, se puede inferir, por tanto, que la actividad de las Comisiones bilaterales ha sido más bien escasa, así que queda en tela de juicio la idea de que las comisiones representen una herramienta efectiva de conexión bilateral vertical entre Estado y Comunidades Autónomas estable y fuerte ${ }^{71}$. Además, en todos los casos (con la excepción de la

67 Las reuniones se han celebrado el: 26/2/2007, 16/4/2007, 17/7/2007, 10/1/2008, 30/7/2008, 24/2/2009, 21/7/2009, 19/7/2011. Vid.: <http://www.seat.mpr.gob.es/portal/politicaterritorial/autonomica/coop autonomica/comisiones bilaterales/Catalunya.html> [Último acceso: 28.7.2020].

${ }^{68}$ En este sentido, Corretja, Vintró, Bernadí, "Bilateralidad y multilateralidad. La participación de la Generalitat en políticas y organismos estatales, y la Comisión Bilateral", cit.; Aragonés Seijo, "El principio de bilateralidad en la reforma de los Estatutos de Autonomía", cit., p.44 ss.

${ }^{69}$ Reunión de 1/8/2018.

Vid.:

$<$ http://www.seat.mpr.gob.es/portal/politicaterritorial/autonomica/coop autonomica/comisiones bilaterales.html> [Último acceso: 28.7.2020].

71 Vid.: M. J. García Morales, Instrumentos y vías de institucionalización de las relaciones intergubernamentales, en X. Arbós Marín, (coord.) Las relaciones intergubernamentales en el estado autonómico. La posición de los actores, Colección Institut d'Estudis Autonòmics 64, Institut d'Estudis 
Comisión bilateral de Aragón), se apreció un periodo de estancamiento en los años siguientes a la STC 31/2010 y, en general, en el periodo de la crisis económica y de la recentralización competencial del Estado que ha señalado la doctrina ${ }^{72}$, más recientemente seguido de una tímida reapertura del diálogo a partir de 2018/2019, con el cambio de gobierno y una mayor voluntad política para reparar el vínculo institucional entre el centro y las periferias.

Sin embargo, gracias al impulso de la reforma del art. 33.2 de la Ley Orgánica del Tribunal Constitucional (LOTC), se observa un papel más activo de las Comisiones bilaterales de cooperación en su vertiente específica de organismos de prevención o reducción de los conflictos competenciales en un ámbito extrajudicial, a través de las correspondientes subcomisiones (en el caso catalán: la Subcomisión de Seguimiento Normativo, Prevención y Solución de Conflictos). La doctrina que ha estudiado el tema coincide en que la actividad de las Comisiones bilaterales está en la práctica casi totalmente absorbida por esta clase de funciones ${ }^{73}$.

Sin embargo, la práctica destaca datos heterogéneos en función de la Comunidad Autónoma, pudiendo observarse un uso escaso o más intenso de este mecanismo, según si la Comunidad prefiere anteponer el intento de conciliación en la Comisión bilateral a la interposición del recurso constitucional.

Sin embargo, como en el caso de las Comisiones bilaterales reunidas a título general, se trata de iniciativas y voluntades políticas que no dependen de cuánto o cómo se regule el funcionamiento de estos órganos de enlace en la Constitución, en los Estatutos o en la legislación ordinaria, sino de la intención real de las partes de cooperar.

Las subcomisiones de prevención y solución de conflictos se reúnen por iniciativa de cualquiera de las dos Administraciones (estatal o autonómica) dentro de los tres

Autonòmics. Barcelona, 2009; Aragonés Seijo, "El principio de bilateralidad en la reforma de los Estatutos de Autonomía", cit., 11 ss.

72 En este sentido vid.: L. Casado Casado en La recentralización de competencias en materia de protección del medio ambiente, cit.

73 En este sentido: M. González Beilfuss, "La resolución extrajudicial de las discrepancias competenciales entre el Estado y las Comunidades Autónomas: el mecanismo del artículo 33.2 de la LOTC", en J. Tornos Mas, (dir.) Informe Comunidades Autónomas 2007, Instituto de Derecho Público. Barcelona, 2008, pp. 17-45. 
meses siguientes a la publicación de la Ley, disposición o acto con fuerza de Ley contra el que se pretende recurrir. El acuerdo sobre iniciación de negociaciones para resolver las discrepancias es puesto en conocimiento del Tribunal Constitucional, determinando así la ampliación del plazo para el recurso (tres meses) en el plazo de nueve meses. Este plazo también marca el cierre de las negociaciones entre Estado y Comunidad y, en caso de resultado positivo, la aprobación de un acuerdo con el que se resuelva la controversia.

Los acuerdos tienen, en la mayoría de los casos, un contenido ${ }^{74}$ interpretativo de las normas objeto de conflicto entre Estado y Comunidad Autónoma, es decir, identifican la interpretación de las disposiciones que las partes consideran acordes con la protección de las competencias de cada una, o prevén el compromiso de modificar el texto de las disposiciones que generaron la divergencia de posiciones (compromiso asumido solo por las Comunidades, nunca por el Estado), o incluso la adopción de un futuro desarrollo reglamentario que aclare la norma objeto de litigio (aunque pocas veces el Estado, que ha asumido este compromiso en relación con los reglamentos en materia ambiental) ${ }^{75}$.

Son centenares los acuerdos firmados en los últimos veinte años (a partir de la reforma del art. 33.2 LOTC) por estas subcomisiones (Gráfico 2), con un incremento considerable a lo largo de los años. Por lo tanto, los acuerdos constituyen en muchos casos una vía alternativa al planteamiento del conflicto ante el Tribunal Constitucional.

Sin embargo, considerando que el uso de las Comisiones bilaterales no ha reducido las disputas constitucionales ${ }^{76}$, el nivel general de conflictos entre el Estado y las Comunidades Autónomas se ha mantenido elevado.

74 Vid: Molés, "Contenido y eficacia de los acuerdos de las Comisiones bilaterales en el procedimiento del artículo 33.2 LOTC", cit., 46 ss.

75 Por ejemplo, los acuerdos con Galicia y Andalucía de 2007 sobre la ley 5/2007, de la Red de Parques Nacionales; el acuerdo con Canarias de 2007 sobre la misma ley y el acuerdo con País Vasco sobre la ley 2/2013 de protección y uso sostenible del litoral y de modificación de la Ley 22/1988, de Costas, que prevén la definición de algunos criterios a incluir en el futuro reglamento; y el acuerdo con Andalucía de 2015 sobre la ley 30/2014, de Parques Nacionales.

${ }^{76}$ Vid. los Boletinos informativos y las Memorias del Tribunal Costitucional entre los años 1981-2019, accesible en <https://www.tribunalconstitucional.es/es/jurisprudencia/Paginas/BD.aspx> y en 
Por otra parte, los acuerdos no siempre evitan el litigio, ya que también pueden afectar solo a una parte de las disposiciones controvertidas y, por lo tanto, es posible recurrir al Tribunal Constitucional por disposiciones no incluidas en el acuerdo o, en el caso de las regulaciones estatales, el acuerdo alcanzado con una Comunidad no limita la posibilidad de que otras puedan interponer recurso. Finalmente, los acuerdos se centran en aspectos puntuales, no en la estructura general de una ley o en temas que involucran una divergencia política y competencial sustancial: estos conflictos conducen en todos los casos ante el Tribunal Constitucional.

Un examen diacrónico de los acuerdos suscritos en los últimos veinte años destaca otros aspectos relevantes para la comprensión de las relaciones institucionales entre el Estado y las Comunidades Autónomas. Estamos asistiendo, en primer lugar, a un aumento en el número de leyes estatales que se negocian de forma bilateral, principalmente por la iniciativa de algunas Comunidades más activas que otras (en especial: Canarias, Cataluña, País Vasco, Galicia y Andalucía). Además, como también confirma el análisis del caso catalán, el Estado activa la negociación en subcomisiones bilaterales en muchos más casos que las Comunidades Autónomas (casi el doble). Sin embargo, se alcanza más fácilmente un acuerdo si la divergencia se refiere a las normas autonómicas, mientras que en el supuesto que sea controvertida la normativa estatal es menos usual (entre el $20 \%$ y el $30 \%$ ).

Este último dato puede explicarse por el diferente peso contractual de las partes y por el hecho de que el Estado se encontraría con más obstáculos en los posibles resultados de la negociación, ya que como se anticipó, el Gobierno del Estado nunca asume compromisos de modificación de una ley (compromiso que requeriría en la fase de implementación posterior al acuerdo la intervención del Parlamento, que podría promover posiciones contrarias) y sólo en raras ocasiones se compromete a adoptar reglamentos (que normalmente en materia ambiental, serían competencia de las Comunidades Autónomas).

<https://www.tribunalconstitucional.es/es/memorias/Paginas/default.aspx> [última consulta el 25.7.2020]. 
Finalmente, en el contexto de la variabilidad de los datos referentes a las Comunidades Autónomas distintivas, se observa en general un bajo número de acuerdos en materia de medioambiente (Gráfico 2), especialmente para Catalunya, considerando que la política medioambiental se encuentra entre las más conflictivas a lo largo de los años ${ }^{77}$.

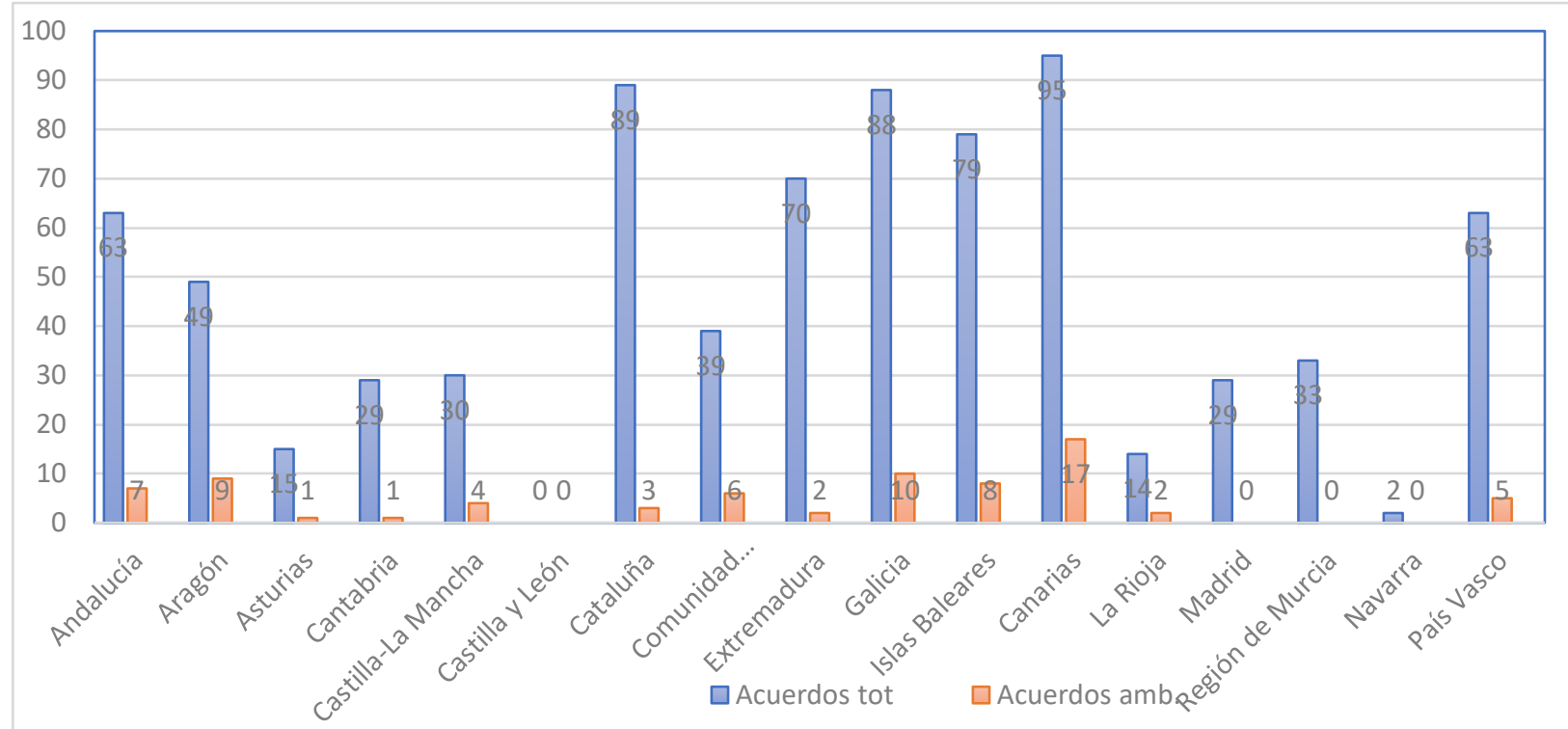

Gráfico 2 (Fuente: elaboración propia): Acuerdos suscritos entre los años 2000-2020.

\section{LA COOPERACIÓN HORIZONTAL: UNA APROXIMACIÓN}

Pretendemos concluir el panorama general sobre la praxis de las relaciones intergubernamentales comentando algunas cuestiones relacionadas con la cooperación horizontal entre las Comunidades Autónomas.

Ya se ha dicho que la prohibición contenida en el art. 145.1 CE - según el cual las Comunidades no pueden establecerse como federación, prohibición a la que sigue, en el apartado segundo del mismo artículo, una disposición bastante farragosa y

\footnotetext{
77 Por ejemplo, entre los años 1981-2003 la materia de medio ambiente ocupa la cuarta posición en las materias más conflictuales. Vid:: M. A. Fernández - J. A. Ramos Gallarín, "El marco de las relaciones intergubernamentales de la política de medio ambiente en el Estado autonómico", cit., 95.
} 
opaca sobre cooperación horizontal ${ }^{78}$ - no favoreció la cooperación entre distintas Comunidades Autónomas.

Tal como ha afirmado también el Tribunal Constitucional ${ }^{79}$, la norma no habilita a las Comunidades a celebrar convenios o acuerdos entre sí, sino por un lado, delimita los requisitos para regular esta materia en los Estatutos y, por otro, establece el control de las Cortes Generales sobre los acuerdos de cooperación.

La norma constitucional no clarifica el discrimen conceptual entre convenios y acuerdos, tampoco establece cuando sea necesaria la autorización de las Cortes Generales; adicionalmente, remite a los Estatutos la definición de los supuestos, de los requisitos y de las modalidades según las cuales celebrar los convenios, así como el carácter y efectos de la comunicación a las Cortes Generales.

Por lo tanto, esta opacidad inicial de la Constitución y la consiguiente remisión a los Estatutos, pueden ser considerados, de acuerdo con la doctrina prevalente, como las causas primigenias de un sistema jurídico dispar y no idóneo para promover la cooperación horizontal entre Comunidades Autónomas ${ }^{80}$.

Además, la escasez de cooperación horizontal ha sido justificada por la doctrina sobre la base de la falta de una tradición de cooperación territorial, la tendencia competitiva entre Comunidades, la voluntad de perseguir sus propios intereses

78 Sobre las cuestiones que plantea el art. 145.2 CE, vid.: A. Sánchez Navarro, "Artículo 145. Convenios entre Comunidades Autónomas", en Óscar Alzaga Villamil, (dir.), Comentarios a la Constitución Española de 1978, XI, Edersa. Madrid, 1999; J. Tajadura Tejada, "El artículo 145 de la Constitución Española: los convenios y acuerdos de cooperación entre las CC.AA.", en Revista Jurídica de Navarra, 21, 1996; C. Gutiérrez Vicen, "La Intervención de las Cortes Generales en la celebración de convenios entre Comunidades Autónomas: la aparición de nuevos problemas", en Corts, Anuario de Derecho Parlamentario, 9, 2000, 283 ss.

79 STC 44/1986.

80 Vease: I. González García, "Un distingo constitucionalmente relevante: los convenios de colaboración vs. Acuerdos de cooperación entre Comunidades Autónomas", en Revista de Estudios Políticos, núm. 145, 2009, pp. 97-118; Id., Convenios de cooperación entre Comunidades Autónomas. Una pieza disfuncional de nuestro Estado de las Autonomías, Centro de Estudios Políticos y Constitucionales. Madrid, 2006; E. Alberti Rovira, "Los convenios entre Comunidades Autónomas", en Documentación Administrativa, núm. 240, 1994, pp. 109 ss.; A. Menéndez Rexach, Los convenios entre Comunidades Autónomas, Instituto de Estudios de Administración Local. Madrid, 1982; J. Tajadura Tejada, "Los convenios de cooperación entre Comunidades Autónomas: Marco normativo y propuestas de reforma”, en Revista d'Estudis Autonòmics i Federals, núm. 11, 2010; P. Santolaya Machetti, Descentralización y cooperación, IEAL, Madrid, 1984. 
específicos en las relaciones bilaterales con el Estado, y la ausencia de leyes y herramientas adecuadas ${ }^{81}$.

Sin embargo, esta percepción negativa de las relaciones autonómicas ha sido cuestionada desde la última oleada de reforma de los Estatutos de Autonomía. La previsión estatutaria de un deber de comunicación en los registros autonómicos ${ }^{82}$ de los instrumentos de cooperación (convenios de colaboración y acuerdos) suscritos ha aflorado una mayor propensión a cooperar que la que se había experimentado previamente ${ }^{83}$, así como la existencia de relaciones previas, aunque informales, basadas en instrumentos de derecho privado y por tanto definidas como "colaboración sumergida" 84 .

${ }^{81}$ Ex multis: Ridaura Martínez, "Las relaciones horizontals de colaboración entre Comunidades Autónomas: marco jurídico, funcionamento y rendimiento", cit:; M. Contreras, "Las relaciones entre las Comunidades Autónomas: un reto pendiente en el Estado Autonómico", en II Jornadas sobre los Estatutos de Autonomía, Dirección General de Desarrollo Autonómico, 2008; P. Ibáñez Buil, "Los convenios entre Comunidades Autónomas", en Revista de Estudios de la Administración Local y Autonómica, núm. 274-275, 1997, 492; E. Aja, M. J. García Morales, "Las relaciones entre Comunidades Autónomas: problemas y perspectivas", en Informe Comunidades Autónomas 2000, Instituto de Derecho Público, Barcelona, 2001, 645-672.

82 Por ejemplo, los Registros de convenios de colaboración y cooperación: de Cataluña (Decreto $52 / 2005$, "de creación y regulación del Registro de convenios de colaboración y cooperación", modificado por el Decreto 322/2006), de Galicia (Decreto 126/2006, "por el cual se regula el Registro de Convenios de la Xunta de Galicia"), de Castilla-La Mancha (Decreto 315/2007, "de Registro General de Convenios de la Administración de la Junta de Castilla-La Mancha"), de las Islas Baleares (Decreto 49/2010, del Gobierno Balear, "de creación y regulación del Registro de convenios de colaboración con el Estado y las Comunidades Autónomas y el Registro de acuerdos de colaboración con Administraciones y entidades públicas extranjeras"); de Castila y León (Decreto 30/2010, "por el cual se regula el Registro General de Convenios de la Administración de la Comunidad de Castilla y León"); de Navarra (Decreto Foral 43/2010, "por el que se regula el Registro de convenios y acuerdos de la Administración de la Comunidad Foral de Navarra"); de Canarias (Decreto 160/2010, "de organización y funcionamiento del Registro de convenios de colaboración con el Estado y las Comunidades Autónomas"); de Aragón (Decreto 57/2012, del Gobierno de Aragón, "por el que se regula el Registro General de Convenios de la Comunidad Autónoma de Aragón").

83 Vid.: C. Colino Cámara, “¿Hacia la normalidad federal? La existencia y el surgimiento reciente de nuevos mecanismos para la cooperación horizontal entre CCAA", in J. Tudela et al. (dir.) España y modelos de federalismo, Forum of Federations/CEPC/Gimenez Abad, 2010; Id., "Federalismo horizontal en el Estado autonómico. La evolución de los mecanismos de cooperación horizontal en España", en Cuadernos Manuel Giménez Abad, núm. 2, 2011; F. J. Matia Portilla, "La cooperación horizontal: Un impulse tan necesario como esperado", en Revista Jurídica de Castilla y León, 23, 2011; Ruiz González, J. Gabriel, "Logros y retos de las conferencias intergubernamentales en España", en GIGAPP Estudios/Working papers, Madrid, 2013. Más recientemente vid. G. G. Carranza, "Las oportunidades del principio de cooperación en el Estado autonómico", en Cuadernos Manuel Giménez Abad, 18, 2018, 67-87.

84 Vid:: M. J. García Morales, "La colaboración a examen: Retos y riesgos de las relaciones intergubernamentales en el Estado autonómico", en Revista Española de Derecho Constitucional, núm. 86, 2009, 79. 
Entre las políticas públicas objeto de mayor actividad de cooperación (administrativa), a la que se asocia la celebración de convenios y acuerdos, figura la materia ambienta| ${ }^{85}$. En este contexto, la cooperación suele afectar a dos o tres Comunidades vecinas, que tienen que gestionar asuntos comunes o espacios naturales protegidos, como es el caso del Parque Nacional de los Picos de Europa entre Cantabria, Castilla-León y Asturias ${ }^{86}$, o del caso más reciente del acuerdo entre las Comunidades de Madrid, Castilla-La Mancha y Castilla y León para reforzar la coordinación en la prevención y extinción de incendios forestales en las zonas limítrofes de las tres regiones ${ }^{87}$.

La cooperación entre Comunidades es más amplia y se intensifica en función de la consecución de una posición común a ser presentada al Estado en la fase ascendente del proceso de participación europea. Finalmente, la cooperación horizontal cobró mayor importancia con el inicio del proceso de encuentros entre Comunidades Autónomas en 2008, identificado con el nombre de "Encuentros entre las Comunidades Autónomas para el desarrollo de sus Estatutos de Autonomía"88, en el que se han aprobado convenios y protocolos para definir una posición común sobre temas relevantes como aquellos relativos a la distribución de competencias entre Estado y Comunidades. En la reunión de 2010 se constituyó la Conferencia de los Gobiernos de las Comunidades Autónomas, que mantuvo la primera reunión el año siguiente ${ }^{89}$, formalizando, de esta manera, la cooperación multilateral horizontal autonómica ${ }^{90}$.

\footnotetext{
85 Vid:: Colino Cámara, "Federalismo horizontal en el Estado autonómico. La evolución de los mecanismos de cooperación horizontal en España", cit., 51.

${ }^{86}$ Convenio suscrito después de STC 194/2004.

87 Véase el acuerdo entre las Comunidades de Madrid, Castilla-La Mancha y Castilla y León para reforzar la coordinación en la prevención y extinción de incendios forestales en las zonas limítrofes de las tres regiones. Vid.: <https://www.comunidad.madrid/noticias/2020/06/26/diaz-ayuso-firmaacuerdo-castilla-mancha-castilla-leon-extincion-incendios> [última consulta el 25.7.2020].

88 Inicialmente, los encuentros fueron promovidos por las siguientes seis Comunidades Autónomas: Andalucía, Aragón, Castilla-León, Cataluña, Comunidad Valenciana, Islas Baleares.

${ }^{89}$ En 2011, en Santander.

90 Para un commentario vid: X. De Pedro Bonet, "La Conferencia de los Gobiernos de las Comunidades Autónomas", en Informe Comunidades Autónomas 2010, Instituto de Derecho Público. Barcelona, 2011, p. 94.
} 
Las iniciativas y experiencias recordadas demuestran un tejido relacional entre Comunidades de ninguna manera insignificante. Sin embargo, la dinámica cooperativa todavía parece muy fragmentada y frágil en comparación con el sistema de interacciones existente todavía marcado por la competitividad. De hecho, la cooperación horizontal entre las Comunidades Autónomas se caracteriza por ser sobre todo de carácter puntual y orientada a la resolución de problemas territoriales comunes únicos.

\section{UN COTEJO CON LOS DATOS DE LA JURISPRUDENCIA CONSTITUCIONAL}

Al combinar el análisis anterior con algunos datos cuantitativos de la jurisprudencia constitucional ambiental ${ }^{91}$, es posible comprender de forma más sólida y clara la evolución del "estado de salud" de las relaciones cooperativas autonómicas en el ejercicio de las competencias ambientales compartidas.

Comparado con el contencioso total, la materia ambiental se ubica, como se ha anticipado, entre las más conflictivas de la historia de la jurisprudencia constitucional española, ya que en el periodo de cuarenta años alcanza un total de poco menos de 200 impugnaciones entre recursos y planteamientos de conflictos.

Si examinamos el perfil diacrónico, ante la sustancial continuidad en el dato global de recursos contra las leyes estatales y autonómicas y de los conflictos de competencias entre el Estado y las Comunidades Autónomas, durante los últimos veinte años ${ }^{92}$ se observa, al contrario, un leve aumento del contencioso ambiental.

\footnotetext{
${ }^{91}$ El análisis cualitativo de las sentencias ambientales examinadas durante cuarenta años muestra, a su vez, cómo el Tribunal Constitucional ha condicionado la cooperación en materia ambiental a través del contenido material de sus sentencias. En este punto, consulte el trabajo monográfico de la Autora del presente estudio (próxima publicación).

${ }_{92}$ Aunque con alguna distinción en los datos anuales. En detalle, el dato anual de los recursos de inconstitucionalidad (promovidos por el Estado o por las Comunidades Autónomas) y de los conflictos de competencia es el siguiente: 2000 (48), 2001 (38), 2002 (65), 2003 (56), 2004 (59), 2005 (21), 2006 (26), 2007 (31), 2008 (34), 2009 (19), 2010 (33), 2011 (38), 2012 (41), 2013 (77), 2014 (58), 2015 (40), 2016 (42), 2017 (43), 2018 (8), 2019 (27). Vid. Los datos anuales: de las Memorias <https://www.tribunalconstitucional.es/en/memorias/Paginas/default.aspx> y de los Boletines de
} 
En efecto, mientras que el 55\% del total de recursos y conflictos surgidos en el período 1980-2019 se concentró en las dos décadas 1980-1999 y el 45\% en las dos décadas siguientes $2000-2019$, el $42 \%$ de los recursos y conflictos del total de los planteados en materia ambiental en el período 1980-2019 ocurrió en los primeros veinte años, mientras que la parte restante del $58 \%$ en los últimos (Gráfico 3 ).

Gráfico 3 (Fuente: elaboración propia) ${ }^{93}$ : Recursos y conflictos total comparados con los ambiental surgidos entre los años 1980-2019.

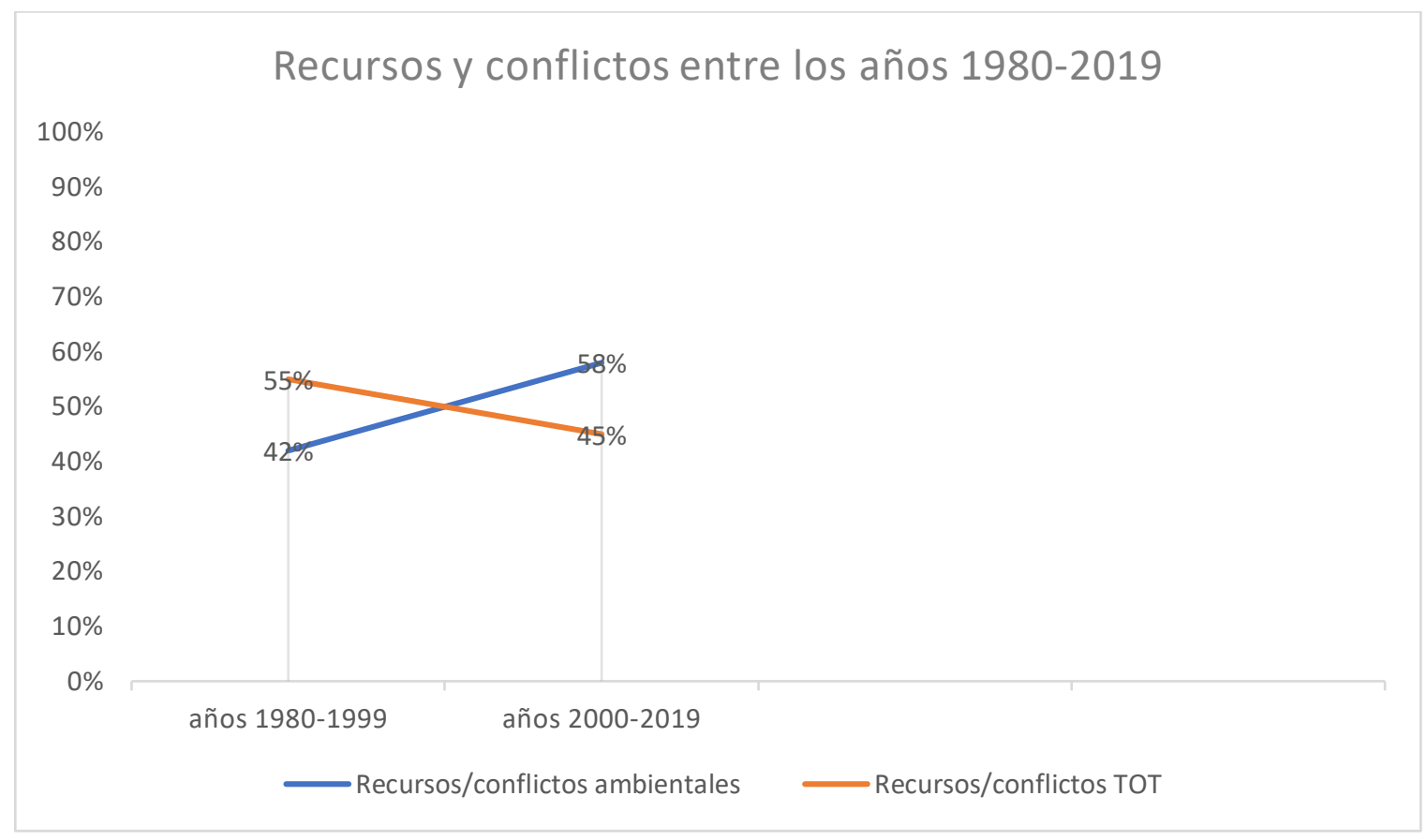

Tomando en consideración el período comprendido entre 2000 y 2019, la conflictividad se distribuye de manera casi constante a lo largo del tiempo (con un promedio de alrededor de 5 recursos por año). Así que la política ambiental

documentación <https://www.tribunalconstitucional.es/es/jurisprudencia/Paginas/BD.aspx> del Tribunal Constitucional [última consulta el 25.7.2020].

93 Elaboración de los datos contenidos en las memorias anuales $<$ https://www.tribunalconstitucional.es/en/memorias> y en los Boletines de documentación $<$ https://www.tribunalconstitucional.es/es/jurisprudencia/Paginas/BD.aspx> del Tribunal Constitucional [Último acceso: 28.7.2020]. 
transversal se confirma, como un ámbito sensible para las relaciones entre el Estado y las Comunidades Autónomas y sigue manifestando a lo largo del tiempo una alta demanda de justicia constitucional.

La cooperación destinada a evitar el establecimiento de conflictos ante el Tribunal Constitucional se ha traducido a partir de 2007 en la firma de alrededor de un centenar de acuerdos bilaterales (de conformidad con el art. 33.2 LOTC). En consecuencia, la falta de atenuación de conflictividad observada anteriormente permite deducir que dicha conflictividad entre el Estado y las Comunidades Autónomas no solo no ha disminuido, sino que ha aumentado con el tiempo, ya que los instrumentos deflacionarios, aunque de uso generalizado, no han sido capaz de reducir el número de impugnaciones.

En cambio, las disputas registradas entre las Comunidades Autónomas resultan escasas, pues, en cuarenta años ${ }^{94}$, se sitúa en menos de una docena de casos, con una concentración en los primeros veinte años y solo un caso entre 2000 y 2019.

El análisis cuantitativo de la conflictividad constitucional combinado con el análisis de las relaciones intergubernamentales también revela otro aspecto de las relaciones entre Estato y Comunidades Autónomas: algunas Comunidades alimentan mucho más que otras los litigios ante el Tribunal Constitucional (Cataluña en primer lugar, seguida de Andalucía, Aragón y País Vasco). Catalunya sola, entre los años 1981-2000, ha impulsado 2 recursos y 7 conflictos en materia medioambiental, mientras que en los últimos veinte años (2001-2019) ha interpuesto 10 recursos y planteado 11 conflictos. Entre las otras comunidades más activas en interponer recursos ${ }^{95}$, Andalucía suma 14, Aragón 12, las Islas Canarias 9, mientras Galicia y País Vasco 6 cada uno ${ }^{96}$.

En cambio, los recursos ${ }^{97}$ interpuestos por el Estato contra leyes autonómicas afectan en particular a Cataluña (10: de los cuales 8 en las últimas dos décadas,

\footnotetext{
${ }^{94}$ Los casos totales son 7 (años 1981-1994: 5, 1995-1998: 0, 1999: 1; 2000-2019: 1).

${ }^{95}$ Los reunidos en la misma sentencia ha sido computados solo una vez.

96 Siguen las Islas Baleares (4), Cantabria (4), Castilla-La Mancha, Castilla y León, Comunidad Valenciana, La Rioja ed Extremadura (3 impugnaciones cada una respectivamente) y Comunidad de Madrid (1).

${ }^{97}$ Los recursos reunidos en la misma sentencia han sido computados solo una vez.
} 
Islas Canarias (7), Castilla-La Mancha (7), Pais Vasco (5), Galicia (4), Islas Baleares $(4)^{98}$. Son las mismas Comunidades que han celebrado la mayoría de acuerdos bilaterales con el Estado (ex art. 33.2 LOTC), a excepción de Cataluña que ha firmado solo tres.

\section{CONCLUSIONES}

$\mathrm{Si}$, como hemos dicho, la Constitución Española se caracteriza por una cierta apertura y flexibilidad y por un cierto grado de "indeterminación" en cuanto a la división de competencias y relaciones entre el Estado y las Comunidades Autónomas y entre las propias Comunidades, este carácter genérico ha dado lugar y sigue generando incertidumbres inevitables en el ejercicio de sus respectivas competencias, especialmente en materia ambiental.

En concreto, el análisis de las relaciones intergubernamentales realizado en las páginas anteriores muestra que el nivel de colaboración entre el Estado y las Comunidades Autónomas y entre las distintas Comunidades es mayor de lo que podría desprenderse únicamente de los datos jurisprudenciales. De hecho, a menudo se ha prestado atención al número de conflictos constitucionales, ignorando los acuerdos celebrados a nivel interinstitucional, especialmente en el contexto de conferencias sectoriales y comisiones bilaterales. Más allá de los datos jurisprudenciales sobre los conflictos, debe observarse que los acuerdos y convenios concluidos siguen siendo un indicio de un espíritu colaborativo que perdura en el tiempo y que también involucra la política ambiental, en una medida no preponderante, pero tampoco despreciable.

Sin embargo, cabe recordar que estas formas cooperativas intervienen principalmente en los casos en que las competencias ya están definidas y tienen

98 Castilla y León, Andalucía, Cantabria, Aragón, Región de Murcia y Navarra (3 cada una); Comunidad Valenciana, La Rioja, Comunidad de Madrid, Extremadura y Asturias (2 cada una). 
como objeto planes y programas conjuntos para comprometer actuaciones conjuntas para la consecución de los objetivos comunes, la distribución de subvenciones estatales, o el desarrollo de actuaciones ejecutivas por parte de las Comunidades Autónomas que requieran coordinación con el Estado, pero en las que no exista conflicto de competencias entre las partes. En este sentido, los acuerdos y los convenios no pueden considerarse un instrumento deflacionario de la conflictividad, ya que se refieren a casos en los que es poco probable que se decida el planteamiento de un conflicto ante el Tribunal Constitucional.

A la luz de estos datos, está claro que la cooperación entre los niveles central y autonómico sigue siendo insuficiente para promover la gobernanza multinivel del medio ambiente. El marco de relaciones entre el Estado y la Comunidad sigue estando fuertemente condicionado por tendencias competitivas, por un lado, y por tendencias uniformadoras (centralizadoras) ${ }^{99}$, por otro, que desembocan inevitablemente en recursos y conflictos ante el Tribunal Constitucional.

Estas tendencias, si coexisten y se acentúan como en los últimos años, también anulan los efectos de los instrumentos cooperativos entretanto previstos por la legislación y los Estatutos de Autonomía y comprometen irremediablemente el ejercicio conjunto de la política ambiental por parte del Estado y de las Comunidades Autónomas.

La voluntad del Estado y de las Comunidades Autónomas de retomar el hilo del diálogo y de la cooperación repetidamente deshilachado en los últimos años aparece, por tanto, como el verdadero desafío para abordar eficazmente la cada vez más compleja y urgente cuestión ambiental y climática, así como para limitar el papel preponderante del Tribunal Constitucional en la definición de las propias relaciones interinstitucionales, que, si se observa con atención, contribuye a acentuar aún más las diferencias existentes.

\footnotetext{
99 Para un análisis en profundidad vid. L. Casado Casado en La recentralización de competencias en materia de protección del medio ambiente, cit.
} 


\section{BIBLIOGRAFÍA}

Abellán López, María Ángeles, "Un balance de la modernización autonómica y las tensiones intergubernamentales", Cuadernos de Gobierno y Administración Pública, Vol. 2, Núm. 2 (2015), pp. 65-185.

Aja, Eliseo, Estado autonómico y reforma federal, Alianza, Madrid, 2014.

Aja, Eliseo "La Conferencia de Presidentes del Estado autonómico", en Informe Comunidades Autónomas, Barcelona: Instituto de Derecho Público, 2005, pp. 791801.

Aja, Eliseo, García Morales, María Jesús, "Las relaciones entre Comunidades Autónomas: problemas y perspectivas", Informe Comunidades Autónomas 2000, Instituto de Derecho Público, Barcelona, 2001.

Albertí Rovira, Enoch, "El régimen de los convenios de colaboración entre administraciones: un problema pendiente", Informe Comunidades Autónomas 1995, Instituto de Derecho Público, Barcelona, 1996.

Alberti Rovira, Enoch, "Los convenios entre Comunidades Autónomas", en Documentación Administrativa, núm. 240, 1994, pp. 109 ss.

Alda Fernández, Mercedes, "Los planes y programas conjuntos como instrumentos de cooperación intergubernamental: características y evolución en el Estado Autonómico", Congreso CLAD, Madrid, 2004.

Aragonés Seijo, Ignacio, "El principio de bilateralidad en la reforma de los Estatutos de Autonomía", Institut de Dret Públic Working Papers, 1, 2012, pp. 1-55.

Arbós Marín, Xavier, (coord.), Las relaciones intergubernamentales en el estado autonómico: La posición de los actores, Generalitat de Catalunya, Collecció Institut d'Estudis Autonómics, Barcelona, 64, 2009. 
AA. VV., Las relaciones interadministrativas de cooperación y colaboración: Seminario celebrado en Barcelona el 7 de mayo de 1993, Generalitat de Catalunya, Colleció Institut d'Estudis Autonomics, 1993.

Beltrán Aguirre, Juan Luis, "Los principios organizativos de la Administración social: descentralización, participación, coordinación y cooperación”, 271-272, Documentación Administrativa, 2005, pp. 207-236.

Biglino Campos, Paloma, "La lealtad constitucional en el Estado de las Autonomía", Revista Jurídica de Castilla y León, núm. extraordinario, 2004, 51-74.

Bocanegra Sierra, Raúl - Huergo Lora, Alejandro La Conferencia de Presidentes, lustel. Madrid, 2005.

Carmona Contreras, Ana, "Las relaciones entre las Comunidades Autónomas: un reto pendiente en el Estado Autonómico", en II Jornadas sobre los Estatutos de Autonomía, Dirección General de Desarrollo Autonómico, 2008.

Carranza, Gonzalo Gabriel, "Las oportunidades del principio de cooperación en el Estado autonómico. Revista", Cuadernos Manuel Giménez Abad, 18, 2019, 67-87.

Casado Casado, Lucía, La recentralización de competencias en materia de protección del medio ambiente, Generalitat de Catalunya, Colleció IEA, Barcelona, 2018.

Casas i Rondoní, Marc, "La Comisión Bilateral Generalitat-Estado: Regulación y actividad práctica", Revista Catalana de Dret Públic, 42, 2011, p. 4 ss.

Colino Cámara, César, "Federalismo horizontal en el Estado autonómico. La evolución de los mecanismos de cooperación horizontal en España", Cuadernos Manuel Giménez Abad, 2, 2011.

Colino Cámara, César, “¿Hacia la normalidad federal? La existencia y el surgimiento reciente de nuevos mecanismos para la cooperación horizontal entre CCAA", en J. Tudela et al. (dir.) España y modelos de federalismo, Forum of Federations/CEPC/Gimenez Abad, 2010. 
Colino Cámara, César, "Las relaciones intergubernamentales en España", en J. Tudela Aranda-F. Knüpling, (dir.), España y modelos de federalismo, Fundación Giménez Abad de Estudios Parlamentarios y del Estado Autonómico-Centro de Estudios Políticos y Constitucionales. Madrid, 2010.

Corretja Torrens, Mercè, Pérez Velasco, María del Mar, Cataluña, N. monografico “La colaboración en los nuevos Estatutos, Rev. Jur.de Castilla y León, 19, 2009.

Corretja, M., Vintró, J., Bernadí, X., Bilateralidad y multilateralidad. La participación de la Generalitat en políticas y organismos estatales, y la Comisión Bilateral, Revista d'Estudis Autonòmics i Federals, 12, 2011, pp. 403-446.

De Pedro Bonet, Xavier, "La Conferencia de los Gobiernos de las Comunidades Autónomas", Informe Comunidades Autónomas 2010, Instituto de Derecho Público, Barcelona, 2011, p. 94 ss.

Duque Villanueva, Juan Carlos, "Las Conferencias Sectoriales", Revista Española de Derecho Constitucional, 79, 2007.

Fernández Farreres, Germán, "Las conferencias sectoriales y los consorcios en las relaciones de colaboración entre el Estado y las Comunidades Autónomas", en Las relaciones interadministrativas de cooperación y colaboración, Institut d'Estudis Autonòmics, Barcelona, 1993, pp. 115-168.

Fernández, Mercedes Alda - Ramos Gallarín, Juan Antonio, El marco de las relaciones intergubernamentales de la política de medio ambiente en el Estado autoómico, GAPP 28/29, 2004, 87-104.

Font i Llovet, Tomàs - Merloni, Francesco "Il regionalismo spagnolo tra riforma costituzionale e riforma statutaria", Le Regioni, 33, 6, 2005, pp. 1179-1202.

Gálvez Muñoz, Luis A., Ruiz González, José Gabriel, "Estado autonómico, cooperación intergubernamental y Conferencias de Presidentes", Revista de Derecho Político, 86, 2013, p. 239 ss.

García Mexia, Pablo Luis, "Las relaciones institucionales entre las Comunidades Autónomas. La cooperación interautonómica”, en A.A.V.V., Curso de Derecho 
Publico de las Comunidades Autónomas, INAP-Montecorvo, Madrid, 2003, pp. 533577.

García Morales, María Jesús, "La colaboración a examen: Retos y riesgos de las relaciones intergubernamentales en el Estado autonómico", Rev. Esp. Der. Const., 86, 2009, 65-117.

García Morales, María Jesús, Instrumentos y vías de institucionalización de las relaciones intergubernamentales, en X. Arbós Marín, (coord.) Las relaciones intergubernamentales en el estado autonómico. La posición de los actores, Colección Institut d'Estudis Autonòmics 64, Institut d'Estudis Autonòmics. Barcelona, 2009.

García Morales, María Jesús, "Los nuevos Estatutos de Autonomía y las nuevas relaciones de colaboración. Un nuevo escenario, ¿una nueva etapa?", Revista Jurídica de Castilla y León, núm. 19, 2009, pp. 364-367.

García Morales, María Jesús, "Relaciones de colaboración con las Comunidades Autùnomas", en Informe Comunidades Autónomas, 2005, pp. 72-95.

González Beilfuss, Markus, "La resolución extrajudicial de las discrepancias competenciales entre el Estado y las Comunidades Autónomas: el mecanismo del artículo 33.2 de la LOTC", Informe Comunidades Autónomas 2007, Instituto de Derecho Público, Barcelona, 2008, pp. 17-45.

González García, Ignacio, "Un distingo constitucionalmente relevante: los convenios de colaboración vs. Acuerdos de cooperación entre Comunidades Autónomas”, en Revista de Estudios Políticos, núm. 145, 2009, pp. 97-118.

González García, Ignacio, Convenios de cooperación entre Comunidades Autónomas. Una pieza disfuncional de nuestro Estado de las Autonomías, Centro de Estudios Políticos y Constitucionales. Madrid, 2006.

Gutiérrez Vicen, Carlos, "La Intervención de las Cortes Generales en la celebración de convenios entre Comunidades Autónomas: la aparición de nuevos problemas", Corts, Anuario de Derecho Parlamentario, núm. 9, 2000, p. 283 ss. 
Ibáñez Buil, Pedro, "Los convenios entre Comunidades Autónomas", REAL, 274275, 1997, p. 492 ss.

Jiménez Blanco, Antonio, "De las Administraciones Públicas y sus relaciones", en Comentario sistemático a la Ley de Régimen Jurídico de las Administraciones Públicas y del procedimiento administrativo común, Civitas. Madrid, 1993.

López Nieto, Lourdes, Interdependencia functional en un context de autonomía política: los convenios de colaboración entre el gobierno nacional y las Comunidades Autónomas en el Sistema español de relaciones intergubernamentales, Congreso CLAD, Madrid, 2004.

Máiz Suárez, Ramón, Beramendi Álvarez, Pablo, Grau Creus, Mireia, "La federalización del Estado de las Autonomías: evolución y déficit institucionales", en Subirats Humet, J. y Gallego Calderón, R. (coords.), Veinte años de autonomías en España: leyes, políticas públicas, instituciones y opinión pública, CIS, Madrid, 2002. Matia Portilla, Francisco Javier, "La cooperación horizontal: Un impulso tan necesario como esperado", Revista Jurídica de Castilla y León, núm. 23, 2011, 105144.

Menéndez Rexach, Angel, Los convenios entre Comunidades Autónomas, Instituto de Estudios de Administración Local. Madrid, 1982.

Mondragón Ruiz de Lezana, Jaione et Al., Análisis de las conferencias sectoriales (2001-2012): valores y percepciones de los agentes políticos y técnicos y dinámica de funcionamiento, Instituto Nacional de Administración Pública, Madrid, 2015.

Mondragón Ruiz de Lezana, Jaione et Al., "Entre el liderazgo y la institucionalización: un estudio de caso de las Conferencias Sectoriales de salud, educación y medio ambiente". In Sociedades en constante cambio: realidad social y reto científico: actas del X Congreso vasco de sociología y ciencia política, Universidad del País Vasco/Euskal Herriko Unibertsitatea, 2018, pp. 575-597.

París, Neus, "Les relacions institucionals de la Generalitat en la sentència sobre I'Estatut d'Autonomia de Catalunya", Revista Catalana de Dret Públic, Especial 
Sentència 31/2010 del Tribunal Constitucional, sobre l'Estatut d'Autonomia de Catalunya, 2010.

Pérez Gabaldón, Marta, Los problemas competenciales en materia medioambiental y las relaciones intergubernamentales como posible vía de solución, Valencia, 2011. Pérez Medina, José María, "Dinámica de las conferencias sectoriales. Entre la intergubernamentalidad y la cooperación administrativa", REAF, 2020, 48-48.

Pérez Medina, José María, "Las relaciones de colaboración entre el Estado y las Comunidades Autónomas, desde la perspectiva de la Administración General del Estado", Rev. Jur. de Castilla y León, 19, 2009, p. 326 ss.

Pérez Velasco, Maria del Mar, "Comentari de la Sentència del Tribunal Constitucional que resol el recurs d'inconstitucionalitat presentat pel PP contra I'Estatut d'autonomia de Catalunya: Comissió Bilateral Generalitat-Estat (article 183 EAC)", en Revista Catalana de Dret Públic. Especial Sentència 31/2010 del Tribunal Constitucional, sobre l'Estatut d'Autonomia de Catalunya, 2010

Ramos, Juan Antonio, "Las Comisiones Bilaterales de Cooperación en el sistema español de relaciones intergubernamentales", en L. López Nieto (Coord.): Relaciones intergubernamentales en la España democrática (interdependencia, autonomía, conflicto y cooperación), Dykinson, Madrid, 2006.

Ramos, Juan Antonio, La dimension bilateral de las relaciones intergubernamentales en el Estado autonómico: las Comisiones bilaterales de cooperación, IX Congreso CLAD, Madrid, 2004.

Ridaura Martínez, María Josefa, "Las comisiones bilaterales de cooperación en el sistema autonómico español", Cuadernos constitucionales de la Cátedra Fadrique Furió Ceriol, 60/61, 2007, pp. 65-84.

Ridaura Martínez, María Josefa, Relaciones Intergubernamentales: EstadoComunidades Autónomas, Tirant lo Blanch. Valencia, 2009, pp. 79-80

Roig Molés, Eduard, "Contenido y eficacia de los acuerdos de las Comisiones bilaterales en el procedimiento del artículo 33.2 LOTC", Estudios monograficos, Informe Comunidades Autónomas, 2015, pp. 39-70. 
Romero González, Juan, "El Gobierno del territorio en España. Balance de iniciativas de coordinación y cooperación territorial”, en Boletín de la AGE, 39, 2005, 59-86.

Ruiz González, José Gabriel, "Logros y retos de las conferencias intergubernamentales en España", GIGAPP Estudios/Working papers, Madrid, 2013 Ruiz González, José Gabriel, "La cooperación intergubernamental en el Estado autonómico: situación y perspectivas", REAF, 15, 2012, pp. 287-328.

Sánchez Navarro, Ángel, "Artículo 145. Convenios entre Comunidades Autónomas", en Óscar Alzaga Villamil, (dir.), Comentarios a la Constitución Española de 1978, XI, Madrid, Edersa, 1999.

Santolaya Machetti, Pablo, Descentralización y cooperación, IEAL, Madrid, 1984

Tajadura Tejada, Javier, "Federalismo cooperativo y Conferencias Sectoriales: Marco normativo y propuestas de reforma", Revista Jurídica de Navarra, núm. 49, 2010.

Tajadura Tejada, Javier, El principio de cooperación en el Estado Autonómico, Editorial Comares, 3르. Ed., 2010.

Tajadura Tejada, Javier, "Los convenios de cooperación entre Comunidades Autónomas: Marco normativo y propuestas de reforma", Revista d'Estudis Autonòmics i Federals, núm. 11, 2010;

Tajadura Tejada, Javier, "El artículo 145 de la Constitución Española: Ios convenios y acuerdos de cooperación entre las CC.AA.", Revista Jurídica de Navarra, núm. 21, 1996.

Tornos Más, Joaquín, "Las Conferencias Sectoriales", Documentación Administrativa, 240, 1994.

Zambonino Pulito, María, La articulación de la gobernanza multinivel a través de técnicas orgánicas de colaboración, cooperación y coordinación, Rev Arag. Admin. Pub., 52, 2018, pp. 230-263. 